\title{
Cognitive impairment and dementia in Parkinson's disease: clinical features, diagnosis, and management
}

\author{
Joana Meireles ${ }^{1,2}$ and João Massano ${ }^{1,2,3 *}$ \\ 1 Department of Neurology, Centro Hospitalar de São João, Porto, Portugal \\ ${ }^{2}$ Department of Clinical Neuroscience and Mental Health, Faculty of Medicine University of Porto, Porto, Portugal \\ ${ }^{3}$ Movement Disorders and Functional Surgery Unit, Centro Hospitalar de São João, Porto, Portugal
}

Edited by:

Martin Rhys Farlow, Indiana

University School of Medicine, USA

Reviewed by:

Pablo Martinez, Reina Sophia

Institute, Spain

Jonathan Rohrer, University College

London, UK

\section{${ }^{*}$ Correspondence:}

João Massano, Movement Disorders and Functional Surgery Unit,

Department of Neurology, Centro

Hospitalar de São João, Alameda

Professor Hernâni Monteiro,

4200-319 Porto, Portugal.

e-mail: jmassano@med.up.pt
Parkinson's disease (PD) is a common, disabling, neurodegenerative disorder. In addition to classical motor symptoms, non-motor features are now widely accepted as part of the clinical picture, and cognitive decline is a very important aspect of the disease, as it brings an additional significant burden for the patient and caregivers. The diagnosis of cognitive decline in PD, namely mild cognitive impairment ( $\mathrm{MCl}$ ) and dementia, can be extremely challenging, remaining largely based on clinical and cognitive assessments. Diagnostic criteria and methods for PD dementia and $\mathrm{MCl}$ have been recently issued by expert work groups. This manuscript has synthesized relevant data in order to obtain a pragmatic and updated review regarding cognitive decline in PD, from milder stages to dementia. This text will summarize clinical features, diagnostic methodology, and therapeutic issues of clinical decline in PD. Relevant clinical genetic issues, including recent advances, will also be approached.

Keywords: dementia, diagnosis, diagnostic criteria, mild cognitive impairment, non-motor symptoms, Parkinson's disease, Parkinson's disease dementia, cognition

\section{INTRODUCTION}

Parkinson's disease (PD) is the second most common neurodegenerative disorder, following Alzheimer's disease. Nearly 200 years have gone by since James Parkinson's original clinical depictions in his monograph entitled An Essay on the Shaking Palsy (Parkinson, 1817; Goetz, 2011). The text focused mainly on the motor features of PD, overlooking non-motor symptoms, with the notable exception of "melancholy" - but cognitive impairment was at that time completely disregarded. It is currently recognized that the spectrum of non-motor features in PD is broad (Chaudhuri and Schapira, 2009; Tolosa et al., 2009; Massano and Bhatia, 2012), but these may often be missed in clinical practice. Nonetheless, whenever PD is suspected, the routine approach should include a set of questions aimed at exploring their presence, since they may be helpful hints for the diagnosis, although they are non-specific in this regard. On the other hand, it is useful to quantify their severity and impact, as they carry an important additional burden on the patients, leading to significantly deteriorated quality of life (QOL), and warranting specific therapeutic interventions, despite the fact that evidence-based data on treatment are unsatisfactory in many instances (Chaudhuri and Schapira, 2009; Tolosa et al., 2009; Zesiewicz et al., 2010). Braak and coworkers have greatly contributed to the awareness of the association between symptoms and the neuropathological lesions affecting the nervous system (Braak et al., 2003; Hawkes et al., 2010). Indeed, due to long term progression and the mode of pathological spreading, some of the non-motor features of PD may be present before any of the classical motor signs are noticeable, sometimes for years or even decades, which may lend them potential utility as supportive diagnostic features in early disease stages - these include hyposmia, rapid eye movement (REM) sleep behavior disorder, constipation, and depression (Chaudhuri and Schapira, 2009; Lim et al., 2009; Tolosa et al., 2009; Hawkes et al., 2010; Savica et al., 2010; Schapira and Tolosa, 2010). Patients may have these and other symptoms before overt motor signs emerge and the clinical diagnosis is finally established. On the other hand, features like dementia and hallucinations tend to occur later in the course of disease, which might be useful for distinguishing PD from other disorders. Cognitive impairment is a major non-motor feature of PD, but the diagnosis is often complex, remaining based on clinical skills and methods, as no reliable diagnostic biomarkers have been described yet. Mild cognitive dysfunction is apparent in many cases from early stages (Aarsland et al., 2009; Barone et al., 2011; Domellöf et al., 2011; Litvan et al., 2011), but recent research has shown that manifest dementia will occur in over $80 \%$ of patients after 20 years of disease (Hely et al., 2008). Accurate cognitive assessment and classification is also paramount in the context of deep brain stimulation for PD, an issue approached in detail in the article by Massano and Garrett (2012), also part of this Frontiers Research Topic. The present manuscript will cover the clinical aspects of cognitive decline in $\mathrm{PD}$, namely mild cognitive impairment (MCI), and dementia (PD-D), including typical features, diagnosis, and management issues.

\section{METHODS}

A comprehensive PubMed literature search was conducted for papers published until September 2011, using the keywords "Parkinson's disease," "Parkinson's disease dementia," "mild cognitive impairment." From all the references found, the authors have consensually chosen those most relevant to the review, in 
order to obtain a clinically oriented perspective of the state of the art knowledge regarding cognitive decline in PD. Exceptionally, later references of interest, published in the meantime, have also been considered.

\section{EPIDEMIOLOGY OF PARKINSON'S DISEASE DEMENTIA}

Due to differences in diagnostic criteria, methodology, and study populations, epidemiological numbers regarding $\mathrm{PD}-\mathrm{D}$ tend to vary greatly. The prevalence of dementia in community-based studies has been estimated at 30-40\% (Aarsland et al., 2005; Aarsland and Kurz, 2010) but figures range from about 10 to $80 \%$ of people with PD (Aarsland et al., 2005; Aarsland and Kurz, 2010). Even in young onset PD, defined as symptoms emerging from 21 to 40 years (Schrag and Schott, 2006), dementia affects up to $19 \%$ of patients after a median of 18 years of disease duration (Schrag et al., 1998). In addition, cognitive decline is noted in up to $36 \%$ of newly diagnosed cases of PD (Reid et al., 1989; Foltynie et al., 2004). From the published literature, it seems clear that the prevalence of dementia increases with age and duration of the disease symptoms (Hughes et al., 2000; Aarsland and Kurz, 2010), although some have suggested that patient age could be preponderant (Aarsland et al., 2007). The Sydney Multicenter Study has been an exceptional initiative in this field of research, as one group of clinicians followed a single cohort of newly diagnosed people with PD over 20 years. Sydney neurologists were asked to refer their newly diagnosed PD patients for a 5-year trial comparing low dose bromocriptine with low dose levodopa/carbidopa (Hely et al., 1994). During this study, neuropsychological assessments were performed at baseline and at 3, 5, 10, and 20 years. At baseline, 26 newly diagnosed PD patients were demented - by current definitions, these would be classified as dementia with Lewy bodies (DLB) cases. A neuropsychological diagnosis of dementia was made on the basis of impairment in memory and at least two other areas of cognitive functioning. A test score at least two standard deviations (SD) below the mean score obtained by the control group was classified as cognitive impairment. The control group consisted of 50 age-, gender-, and education-matched community living people without $\mathrm{PD}$, who were friends or relatives of the patients. If no neuropsychological assessment was carried out, a diagnosis of dementia was based on a Clinical Dementia Rating score of at least 1 , with supporting evidence of gradual cognitive decline sufficient to impair daily functioning. This was sustained by performance in Mini-Mental State Examination (MMSE), letter and category fluency, and clock face drawing. At 20 years, 25 of $30(83 \%)$ surviving patients had become demented and 2 others have developed dementia subsequently (Hely et al., 2008).

In an earlier review of 27 studies, Cummings found a mean prevalence of dementia in PD of $40 \%$, even though at that time studies did not include the identification and exclusion of patients with DLB (Cummings, 1988). The incidence of dementia is increased by 2.8- to 6-fold in those with PD when compared to those without the disease (Aarsland et al., 2005; de Lau et al., 2005; Aarsland and Kurz, 2010). The cumulative prevalence is very high - at least $75 \%$ of the patients with PD who survive for more than 10 years will develop dementia (Aarsland and Kurz, 2010).

Several risk factors for PD-D have been proposed, including certain predominant motor features such as rigidity and gait instability, MCI, and the presence of visual hallucinations (Goetz et al., 2008). Older age is broadly accepted as a risk factor for dementia in PD. Some authors have found parameters such as disease duration, age of onset, and motor symptom severity to be significant risk factors, but published data are at times contradictory (Aarsland and Kurz, 2010). Interesting findings have been brought to light regarding genetics and cognitive decline in $\mathrm{PD}$, a few of them quite recently, as we will further detail in the text.

\section{PARIKINSON'S DISEASE DEMENTIA: CLINICAL FEATURES}

Dementia associated with PD holds suggestive phenotypic cognitive features that make it a recognizable and individualized entity. This issue will be further detailed, focusing on its mode of onset, profile of cognitive deficits, behavioral aspects, and motor phenotype, as well as other features. Dementia adds substantially to the burden of disease for the patient, caregiver, and the community (Aarsland et al., 1999, 2000), thus warranting accurate diagnosis and management.

\section{PATTERN OF ONSET AND PROGRESSION}

The onset of PD-D is insidious, often making it difficult for the patient and the family to evoke when the first signs of cognitive dysfunction started. The evolution is progressive. In one prospective, 4-year study, the mean annual MMSE decline was 1 point in PD subjects without dementia versus 2.3 points in the PD-D group, a figure similar to that seen in patients with AD (Aarsland et al., 2004). During the 5 year follow-up of the CamPaIGN cohort, researchers have found that MMSE scores declined at a mean rate of $-0.3 \pm 0.1$ points per year over the 5.2 years of average observation (Williams-Gray et al., 2009). Dementia in the early stages of $\mathrm{PD}$ is not considered a typical feature of the disease (Massano and Bhatia, 2012); by current consensus definitions, whenever parkinsonism and dementia arise in close temporal relationship, those cases should be classified as DLB, as the diagnosis of PD-D requires the preceding diagnosis of PD followed by the later development of dementia (McKeith et al., 2005; Emre et al., 2007a). Early indicators associated with cognitive decline may include excessive daytime sleepiness (Gjerstad et al., 2002). Visual hallucinations are relatively frequent, as are bizarre but ill-defined misperceptions or psychotic phenomena (such as feeling that there is someone else in the room, when indeed this is not the case). Increasing apathy, impaired attention and concentration, and forgetfulness are also frequent features (Goetz et al., 2008), although memory complaints as initial presentation are less frequent than in DLB and, particularly, AD (Noe et al., 2004). The course of decline in PD-D is relentless and progressive over time. Patients may remain stable for several months, at times with periods of faster worsening with no additional obvious cause (Emre, 2010). Fluctuations occur from day to day and during the same day, which is a similar pattern to that of DLB (Ballard et al., 2002).

Hobson and coworkers have studied a community based cohort of PD patients with and without dementia. They found that standardized mortality ratios (SMR) were significantly higher in PD-D patients than in PD non-demented individuals (SMR 3.10, versus $1.15, p<0.001)$. Life expectancy in younger-onset PD-D (55-74 years old) was significantly lower than in non-demented patients (average 7.5 versus 12.4 years), and the estimated age 
at death was also much lower in the first group (72.4 versus 77.8 years). Differences regarding life expectancy and age at death in older-onset PD-D were less obvious (Hobson et al., 2010). Other authors have also found an increased mortality risk among PD patients with dementia (Levy et al., 2002; de Lau et al., 2005).

\section{COGNITIVE PHENOTYPE OF PARKINSON'S DISEASE DEMENTIA}

Assessment of cognition in PD patients can be a demanding and exhausting mission for both the patient and examiner. Disease symptoms such as tremor, bradykinesia, bradyphrenia, pain, fatigue, sleepiness, and mood disorders, as well as medication effects, can interfere with cognitive performance and testing. Also, timed tests can be seriously affected due to motor slowing, and those depending on motor capacity to perform the task, such as drawing, can be interfered by tremor.

Executive functions have been defined as capacities that "enable a person to engage successfully in independent, purposive, and selfserving behavior," and encompass cognitive processes such as initiation, planning, purposive action, self-monitoring, self-regulation, volition, inhibition, and flexibility (Stuss, 2011). Executive dysfunction has been widely recognized as a very important feature of the cognitive phenotype of PD, even in non-demented patients, although published data has been marred by inconsistencies in definitions and research methods (Kudlicka et al., 2011). The most widely used tests to probe executive functioning in PD have been verbal fluency, digit span backward, Wisconsin Card Sorting Test, Stroop Test, and Trail Making Test (Kudlicka et al., 2011). Accumulated research data has shown that executive dysfunction is a prominent feature in PD-D (Tröster, 2008; Kehagia et al., 2010).

There is clinical and electrophysiological evidence of slowed cognition in PD-D, although this may be apparent even in nondementia stages (Rogers et al., 1987; Owen et al., 1992; O’Mahony et al., 1993; Hanes et al., 1996; Turner et al., 2002). Attentional deficits have been consistently shown in PD-D. In tests such as the letter cancelation test and others, PD-D patients are slower, tend to fluctuate more, and incur on a higher number of errors than $\mathrm{AD}$ subjects, whereas the profile of $\mathrm{PD}-\mathrm{D}$ seems to be similar to that seen in DLB (Ballard et al., 2002; Noe et al., 2004; Bronnick et al., 2007).

Visuospatial function is a term used to describe a wide range of functions that must be assessed by different tests, the unifying feature being that all of them rely on visual function and processing (Jeannerod and Jacob, 2005). Findings from studies pertaining to this matter have shown greater deficits in $\mathrm{PD}-\mathrm{D}$ than $\mathrm{AD}$ patients (Starkstein et al., 1996). It has been shown that visual perception, space-motion, and object-form perception are globally more impaired in PD-D patients than in control subjects, including normal controls and non-demented PD patients, and AD (Mosimann et al., 2004).

In PD-D, short term memory is impaired, both for initial learning and immediate recall. Traditionally, mnesic deficits in PD have been considered to be mainly of retrieval, rather than encoding and storage (Pillon et al., 1993). In PD-D, however, patients may also be impaired on cued recall (Higginson et al., 2005). A large meta-analysis has shown that verbal fluency impairment is more pronounced than that seen in PD non-demented patients; also, semantic fluency seems to be more compromised than phonemic fluency (Henry and Crawford, 2004). Concept formation is also impaired in PD-D (Cahn-Weiner et al., 2002, 2003). The Clock-Drawing Test displays marked changes in PD-D, although it is similar to that found in DLB, and AD. PD-D and DLB patients demonstrate more planning errors, as compared to AD (Cahn-Weiner et al., 2003).

Significant dysphasia is not typically seen in PD-D, and language deficits occur much less frequently in $\mathrm{PD}-\mathrm{D}$ than in $\mathrm{AD}$ (Pillon et al., 1993; Frank et al., 1996; Kramer and Duffy, 1996).

Certain phenotypic characteristics pertaining to cognitive decline have been used to differentiate "cortical" from "subcortical" dementia syndromes (Darvesh and Freedman, 1996; Salmon and Filoteo, 2007; Bonelli and Cummings, 2008). Cortical dementia syndromes display impairments of cognitive domains such as episodic memory, praxis, language, and calculation, whereas subcortical dementias tend to show slowed mental processing speed and frontal lobe changes such as apathy, irritability, and dysexecutive impairment. The "cortical" profile is typical of $\mathrm{AD}$, whereas PD-D and DLB typify the "subcortical" dementia type, but many cases fit the opposite prototype (Janvin et al., 2006). Characteristically, early impairment of episodic memory is seen in $\mathrm{AD}$, in accordance to the pathological changes seen in this disorder (Weintraub et al., 2012). For more details on the clinical features of AD please refer to the manuscript by Alves et al. (2012) included in this Frontiers Research Topic.

\section{BEHAVIORAL OR NEUROPSYCHIATRIC SYMPTOMS Psychotic symptoms}

Hallucinations occur in $45-65 \%$ of PD-D patients, a higher rate than in the general population of PD; these come about usually in the visual perceptual modality (Aarsland et al., 2001a,b,c). In PD patients without dementia, hallucinations are an important predictor for the development of dementia and institutionalization (Giladin et al., 2000). Hallucinations tend to be more common in $\mathrm{DLB}$ than in PD-D and in these more frequent than in $\mathrm{AD}$ (Hirono et al., 1999; Aarsland et al., 2000, 2001a,b; Benoit et al., 2005). Hallucinations in PD-D and DLB tend to present similar characteristics, as they are usually complex and well formed, often colorful moving images, with people and animals being a frequent motif (Williams and Lees, 2005; Janvin et al., 2006). Brief, illdefined peripheral images (de passage) may also occur and be less appreciated by the patient (Fenelon et al., 2000). Delusions seem to be less frequent than hallucinations in $\mathrm{PD}-\mathrm{D}$, and are estimated to occur in about $30 \%$ of patients; this rate is greater than in $\mathrm{AD}$ but lower than in DLB (Aarsland et al., 2001b). Delusional activity in PD-D includes "feeling of presence," phantom boarder (the delusional belief that there are foreign people in the house, who may even interfere with the patient's life, e.g., eat their food or misplace their objects), paranoid, or grandiose delusions; delusional activity may be broad or isolated to a single subject.

\section{Mood and anxiety}

Aarsland and coworkers have conducted a community-based study and have documented major depression in 13\% of PD-D subjects, compared with $9 \%$ of non-demented PD patients. This rate is lower than in $\mathrm{DLB}$, but greater than in $\mathrm{AD}$ (Starkstein et al., 1996; Aarsland et al., 2001a). Dysphoric mood with depressive 
symptoms occurs with approximately the same frequency in PD-D and $\mathrm{AD}(40-58 \%)$ patients (Aarsland et al., 2001b). Anxiety occurs at a similar frequency (30-49\%) as depressed mood, and these symptoms may frequently co-exist in the same patient (Menza et al., 1993; Bronnick et al., 2005). Irritable mood, anger, and aggression are common in $\mathrm{AD}$, but uncommon in PD-D (Engelborghs et al., 2005). Manic or hypomanic mood is infrequently seen in PD-D (Starkstein et al., 1996).

\section{Apathy}

It has been reported in $54 \%$ of patients in a large sample of mild to moderate PD-D (Aarsland et al., 2001b). Prominent apathy is very common in other forms of dementia, including frontotemporal dementia (Kertesz, 2003), progressive supranuclear palsy (Aarsland et al., 2001c), AD (Benoit et al., 2005), and DLB (Engelborghs et al., 2005); thus, this feature is not specific enough to guide diagnosis.

\section{NON-COGNITIVE FEATURES OF PARKINSON'S DISEASE DEMENTIA}

Non-motor complications of PD-D are frequent, and those features are now assumed to be an intrinsic part of the pathological processes involved. Therefore, it seems legitimate to assume that motor and non-motor features must be interrelated. PD-D neuropathological findings are detailed in the manuscript by Taipa et al. (2012), included in this Frontiers Research Topic.

\section{MOTOR PHENOTYPE}

There is the notion that certain motor features, such as postural instability and gait disorder (PIGD) are associated with a faster progression rate of cognitive decline in $\mathrm{PD}$, being a risk factor for dementia (Burn et al., 2006). Levy et al. (2002) have documented that older patients with more severe parkinsonian signs had a relatively increased risk for incident dementia than younger and mildly affected subjects. Tremor predominance as the initial presentation has been associated with a lower risk for cognitive decline in some studies. These patients seem to remain protected against cognitive decline, unless they evolve to the PIGD phenotype (Elizan et al., 1986; Reid et al., 1989; Wood et al., 2002). Clinicopathological studies have shown that dementia is most common in PD patients with akinesia/rigidity than in the tremor dominant and mixed phenotypes (Rajput et al., 2009; Selikhova et al., 2009). Poorer cognitive performance is also associated with poorer outcomes in motor and non-motor domains, as a study by Papapetropoulos et al. (2004) has shown. PD-D also seems to be an independent risk factor for falls; other predictors of cognitive decline include previous falls, longer time from disease onset, and decreased arm swing (Wood et al., 2002; Pickering et al., 2007). For levodopa responsivity, data are inconsistent in showing any pattern that differentiates PD-D patients from PD patients without dementia (Stern et al., 1993; Bonelli et al., 2004). A 3year longitudinal study, however, documented greater cognitive decline in PD patients with less than a 50\% levodopa-induced improvement at baseline (Caparros-Lefebvre et al., 1995). Furthermore, an autopsy study has suggested that loss of levodopa responsivity is correlated with dementia due to greater loss of striatal D3 receptors (Joyce et al., 2002). Although fewer dyskinesias were reported in PD-D patients in a cross-sectional study, a longitudinal study found greater mental deterioration in those PD patients with baseline levodopa-induced dyskinesias (Elizan et al., 1986; Caparros-Lefebvre et al., 1995).

\section{SLEEP DISORDERS}

REM sleep behavior disorder (RBD) is characterized by dream enacting behavior, such as jumping out of bed, talking, or kicking. While in REM sleep, abnormal electromyographic activity is present, thus demonstrating the anomalous absence of muscle atonia during this stage of sleep (Olson et al., 2000; Iranzo et al., 2006; Frauscher et al., 2008). The pathophysiology is thought to be related to lesions inflicted on the brainstem REM sleep centers that inhibit the spinal cord motoneurons and their connections, as these structures are usually damaged in PD (Boeve et al., 2009; Iranzo, 2011).

REM sleep behavior disorder may be idiopathic or linked to several neurodegenerative diseases such as PD, DLB, and multiple system atrophy. A study by Iranzo and collaborators has reported that $45 \%$ of the idiopathic RBD patients studied developed a neurological disorder after a mean of 11.5 years from the reported onset of RBD - PD in nine patients (two of them with dementia), DLB in six, MSA in one, and MCI in four by the end of the 5 year follow-up period. Neuropsychological evaluation disclosed cognitive decline of various degrees of severity; three of the four MCI patients showed visuospatial deficits and short term free recall impairment that benefited from external cues (Iranzo et al., 2006).

Patients with idiopathic RBD usually do not report cognitive problems, but Terzaghi et al. (2008) demonstrated that a visuospatial construction deficit was present in $44 \%$ of the patients who suffered from idiopathic RBD. The cognitive profile found in patients with idiopathic RBD usually comprises visuospatial capacities, verbal memory, attention, and executive function impairment. Usually these subjects show no impairment in semantic memory and language, deficits commonly seen in $\mathrm{AD}$ (Ferrini-Strambi et al., 2004; Weintraub et al., 2012). Similarities have also been found between EEG patterns of idiopathic RBD, with cortical EEG slowing (abundant delta and theta waves) in frontal, temporal, and occipital regions, also found in PD and DLB patients (Kai et al., 2005; Caviness et al., 2007b). Some studies have tried to characterize RBD patients with MCI. Gagnon and coworkers have found that most PD patients (73\%) with RBD display MCI, while many patients with idiopathic RBD (50\%) also show MCI. The main subtypes of MCI seem to be single domain non-amnestic and amnestic in PD, while in idiopathic RBD the predominant subtype was non-amnestic MCI; all these patients displayed predominantly executive-attentional impairment (Gagnon et al., 2009). It is currently accepted that RBD occurs in PD patients with associated MCI and dementia, however RBD may also occur in PD patients with no associated cognitive deficits (Iranzo et al., 2005; Gagnon et al., 2009).

\section{AUTONOMIC SYMPTOMS}

Dementia and significant autonomic features may develop in the course of PD, especially in later stages (Hely et al., 2005; Hawkes et al., 2010), hence one could presumably postulate an association between autonomic symptoms and PD-D. This is however yet to be proven by comprehensive studies. The amount of data on the 
relative frequency of autonomic features in demented compared to non-demented PD patients is scarce. Idiaquez and collaborators have assessed $40 \mathrm{PD}$ patients and 30 age matched controls for cognitive and behavioral manifestations using standardized neuropsychological tools. These subjects were assessed for orthostatic hypotension, heart rate, and responses to deep breathing (SCOPA-AUT): 11 of these patients fulfilled the DSM-IV criteria for dementia and a higher incidence of cardiovascular dysfunction were found amongst demented patients (Idiaquez et al., 2007). The presence of autonomic dysfunction has also been reported in the Sydney multicenter study, after 15 years follow-up. Orthostatic hypotension was found in $35 \%$ and urinary hypotension has also been reported in $41 \%$ of PD patients and these were most frequent among those with higher Hohen and Yahr scores (Hely et al., 2005). In this study, however, it was not specified whether or not autonomic symptoms were more frequent in demented patients.

The pathophysiological mechanisms of autonomic dysfunction seem to be related to typical synuclein deposits throughout the central and peripheral autonomic nervous systems. The extension of these deposits to the limbic and cortical areas may be the cause for the associated development of dementia. Trying to define the neural substrate of autonomic dysfunction is difficult, as both systems may be implicated. Comorbidities are also important, as the presence of symptoms, such as orthostatic hypotension, constipation, and urinary incontinence may be due to other causes besides autonomic dysfunction. For instance, dopaminergic drugs may also cause dysautonomic symptoms, leading to constipation, and urinary incontinence (Winge and Fowler, 2006; Allan et al., 2007).

In summary, $\mathrm{PD}-\mathrm{D}$ patients typically present with dysexecutive syndrome, fluctuating attentional deficits, visuospatial impairment, and memory dysfunction, associated with behavioral symptoms (Emre et al., 2007a), which include depression, anxiety, apathy, delusions, and recurrent prominent complex visual hallucinations that may seem disproportionate to the severity of dementia. PD-D is most frequently associated with the postural imbalance gait disability motor phenotype of PD. The evolution is progressive. These clinical features are in many aspects similar to those seen in DLB, and distinguishing both disorders from each other can be challenging (McKeith, 2005; Metzler-Baddeley, 2007).

\section{DIAGNOSTIC CRITERIA FOR PARKINSON'S DISEASE DEMENTIA}

For a long time, specific diagnostic criteria did not exist for PD-D. Clinicians and researchers had to formally support this diagnosis with the help of generic criteria for dementia, such as those set by the Diagnostic and Statistical Manual of Mental Disorders fourth edition (DSM-IV; American Psychiatric Association, 1994). Finally, criteria aimed specifically at the diagnosis of PD-D have been published in 2007, proposed by a Movement Disorder Society task force. Two levels of clinical diagnostic certainty have been defined: possible and probable PD-D (Emre et al., 2007a). According to this document, the essential defining feature of PD$\mathrm{D}$ is the emergence of dementia in the setting of established PD, as diagnosed according to the Queen Square Brain Bank criteria. Dementia is defined as a syndrome of insidious onset and progressive decline of cognition and functional capacity from a premorbid level, that is not attributable to motor or autonomic symptoms.
Impairment in at least two of the four typically involved cognitive domains (impaired and often fluctuating attention; dysexecutive changes; impaired visuospatial abilities; and impaired free recall that improves with cueing) must be documented without prominent language dysfunction, as demonstrated by clinical and cognitive examination. The authors take into account that the main behavioral or neuropsychiatric symptoms seen in PD-D include visual hallucinations, delusions, apathy, depressed mood, anxiety, and excessive daytime sleepiness. These features are frequent in $\mathrm{PD}-\mathrm{D}$, but their presence is not invariable. The presence of at least one symptom from this set supports, but is not required for, the diagnosis of PD-D. Further details on diagnostic criteria for PD-D can be found in Emre et al. (2007a) and the proposed neuropsychological assessment methods to be carried out with these patients have been published in Dubois et al. (2007), from the same workgroup.

Clinical validation efforts have been carried out from experienced groups in this field, regarding this proposal. Dujardin and coworkers have enrolled 188 PD patients, which have been assessed using the two-step cognitive evaluation recommended by the MDS task force (shorter battery followed by longer comprehensive cognitive assessment battery), recording also the presence or absence of dementia after each step had been taken. After the short battery had been applied $18.62 \%$ of PD patients were suspected of having dementia, whereas $21.81 \%$ fulfilled criteria for probable PD-D following the longer battery. The authors have found that the short battery's sensitivity and specificity were 65.85 and $94.56 \%$, respectively - but using specific cutoff scores the sensitivity would increase considerably without significant loss of specificity, thus suggesting that PD-D can be diagnosed accurately with the shorter battery as well as the longer assessment method. Specifically, an MMSE score $<27$, the inability to recall five words immediately after learning, being unable to generate $>7$ words beginning with "S" within $60 \mathrm{~s}$, the lack of full personal independence in managing antiparkinsonian medications, and age $>69$ years seem to be associated with a high probability of PD-D (Dujardin et al., 2010).

Martinez-Martin and coworkers have compared the MDS criteria for the diagnosis of PD-D with dementia criteria established by the DSM-IV. In this study, 299 PD patients have been enrolled, and the authors have found out that the DSM-IV criteria failed to identify $22 \%$ of patients fulfilling the MDS criteria. False negative cases were older and had more severe motor symptoms, but less psychosis than those true non-demented PD. False positives had less severe motor symptoms than true PD-D, although the difference did not reach statistical significance. These findings suggest that the MDS criteria are more sensitive than DSM-IV for diagnosing PD-D, and that it could be more difficult to diagnose PD-D in older patients, as well as those with less psychotic symptoms or severe motor impairment (Martinez-Martin et al., 2011).

Another clinical study aimed at comparing the diagnostic acuity for PD-D of the eight-item screening checklist proposed by the MDS task force, as compared to full neuropsychological assessment. This is an important issue since comprehensive neuropsychological testing is not widely available in every practice setting, thus short screening tools would be most welcome. The authors have assessed 91 PD patients - of these 7 (7.7\% of all subjects) met criteria for probable PD-D based on the screening 
checklist, whereas 15 patients (16.5\%) were detected using full neuropsychological testing; of note, all patients that met criteria for PD-D according to the screening checklist also did with longer neuropsychological testing (100\% specificity). These results imply that the screening checklist performed at $46 \%$ sensitivity for the diagnosis of PD-D, although agreement was moderate between both methods $(\kappa 0.59, p<0.001)$. The most common reasons for false negative misclassification by the screening checklist were that subjects were not deemed to be free of depression ( 5 patients), they had an MMSE score of at least 26 (6 patients), and they were not rated as impaired in activities of daily living ( 1 patient). Altogether, these results suggest that the screening checklist proposed by the MDS task force for the diagnosis of PD-D is specific when all eight items are met, but sensitivity is low, thus a significant number of false negative cases are to be expected. Therefore, this does not seem to be an ideal screening instrument. The authors have also demonstrated that the sensitivity of this tool could be largely increased if two problem items would be removed (absence of depression, abnormal MMSE score), something that should be considered in future research (Barton et al., 2012).

Ideally, clinicopathological validation studies should also be carried out in the future using the MDS criteria for the diagnosis of PD-D, in order to promote in-depth understanding of their diagnostic acuity. Hopefully, the proposal from the MDS task force will at least bring uniform definitions and methods into clinical care and research in the setting of PD-D.

\section{MILD COGNITIVE IMPAIRMENT IN PD}

In a way somewhat analogous to what can be perceived in the course of Alzheimer's disease, a pre-dementia period exists in PD (see Figure 1). In a wide-ranging manner, MCI can be defined as a cognitive decline from a previous performance baseline, that is considered abnormal for the patient's age, but with retention of normal daily functioning. Such a condition appears to be quite frequent in PD, even in early stages and also prior to the initiation of dopaminergic therapy (Muslimovic et al., 2005; Caviness et al., 2007a; Domellöf et al., 2011; Litvan et al., 2011). In clinical and research settings, the term is applied to PD patients who present cognitive complains and whose neuropsychological examinations confirm the deficits, but PD-D criteria cannot be fulfilled due to the lack of overt functional decline related to cognitive impairment.

Deterioration can occur in a range of cognitive domains. However, non-amnestic single domain MCI seems to be more common than amnestic single domain MCI (Pillon et al., 1993; Caviness et al., 2007a; Litvan et al., 2011). Nonetheless, the predictive value regarding the future risk of dementia of each of the MCI subtypes has not been thoroughly assessed in prospective studies (Barone et al., 2011).

From the published data, it is apparent that most PD patients will develop dementia, provided that enough time elapses since disease onset. Since PD-MCI precedes PD-D, one could postulate that the lifelong cumulative prevalence of PD-MCI must be at least as high as that of PD-D. Approximately 27\% of PD patients will meet criteria for PD-MCI at any given time (Litvan et al., 2011). Aarsland et al. (2010) have reported that PD-MCI affects $25.8 \%$ of PD patients (ranging between 23.5 and $28.8 \%$ ). There is significant variability among the numbers reported, which may be justified by methodological differences, namely definitions used, the cognitive domains assessed, how impairment was defined for the test, and the fact that different patient populations have been enrolled.

An interesting population based study using a sample of 239 newly diagnosed PD patients has found an incidence rate of cognitive impairment of $36 \%$. From this subgroup, $21 \%$ scored 1 or more SD below the mean on a pattern recognition memory test, being subsequently classified as having temporal lobe impairment. Thirteen percent scored below the cut off score on a test evaluating frontostriatal deficit, and 15\% were impaired in both tests, suggesting a more global impairment (Foltynie et al., 2004). A second study used an extensive neuropsychological test battery to compare the performance of a sample of 115 newly diagnosed PD$\mathrm{D}$ patients (mean disease duration of 19 months) and 70 healthy controls. Using a definition for impairment as $<2$ SD below the normative sample mean score on at least 3 tests, $\mathrm{PD}$ patients performed significantly worse across most tests, and $24 \%$ of them were deemed cognitively impaired. The patient group performed worse in executive function, memory, complex attention, and psychomotor speed tests (Muslimovic et al., 2005). Several studies have found that increasing age, late disease onset, severity of PD, and lower educational level are risk factors associated with PDMCI (Pai and Chan, 2001; Foltynie et al., 2004; Muslimovic et al., 2005; Mamikonyan et al., 2009).

The complexity of defining MCI in early stages of PD is high, for significant confusion with early DLB should be anticipated. On the other hand, there is a concern that the definitions used to determine MCI may lack sensitivity to detect early cognitive decline in high functioning people, as these have to suffer added decline before they reach the defined cutoff below normative means. Hence they may potentially be classified cognitively unimpaired when in fact a decline from baseline performance has already occurred. It is commonly argued that high functioning people may have additional protection from dementia - but their work and social settings also tend to be more demanding, and subtle cognitive decline may thus become more apparent. Importantly, the clinical definition of MCI requires that the person has experienced a change in cognition, compared to baseline (Litvan et al., 2011).

\section{PROFILE OF COGNITIVE IMPAIRMENT}

A number of studies assessing cognitive functioning in nondemented PD have been published. Cognitive deficits in PD are traditionally seen as subcortical in their nature, as several studies have demonstrated that there is a significant impairment in executive functions such as poor planning, sequencing, cognitive flexibility, and problem solving capacities (Pai and Chan, 2001; Muslimovic et al., 2005; Barone et al., 2011). Memory impairments, including encoding, recall, and procedural memory are also affected (Foltynie et al., 2004). Recognition is thought to remain relatively well preserved (Foltynie et al., 2004). Language dysfunction is rarely reported, with an exception of deficits in phonemic and semantic tasks, which exist and tend to decline over time and with disease severity, as evaluated by the Hoehn and Yahr stage, predicting also a future diagnosis of dementia (Barone et al., 2011).

Identifying PD-MCI is clinically relevant, given that these patients appear to be at increased risk for developing PD-D 


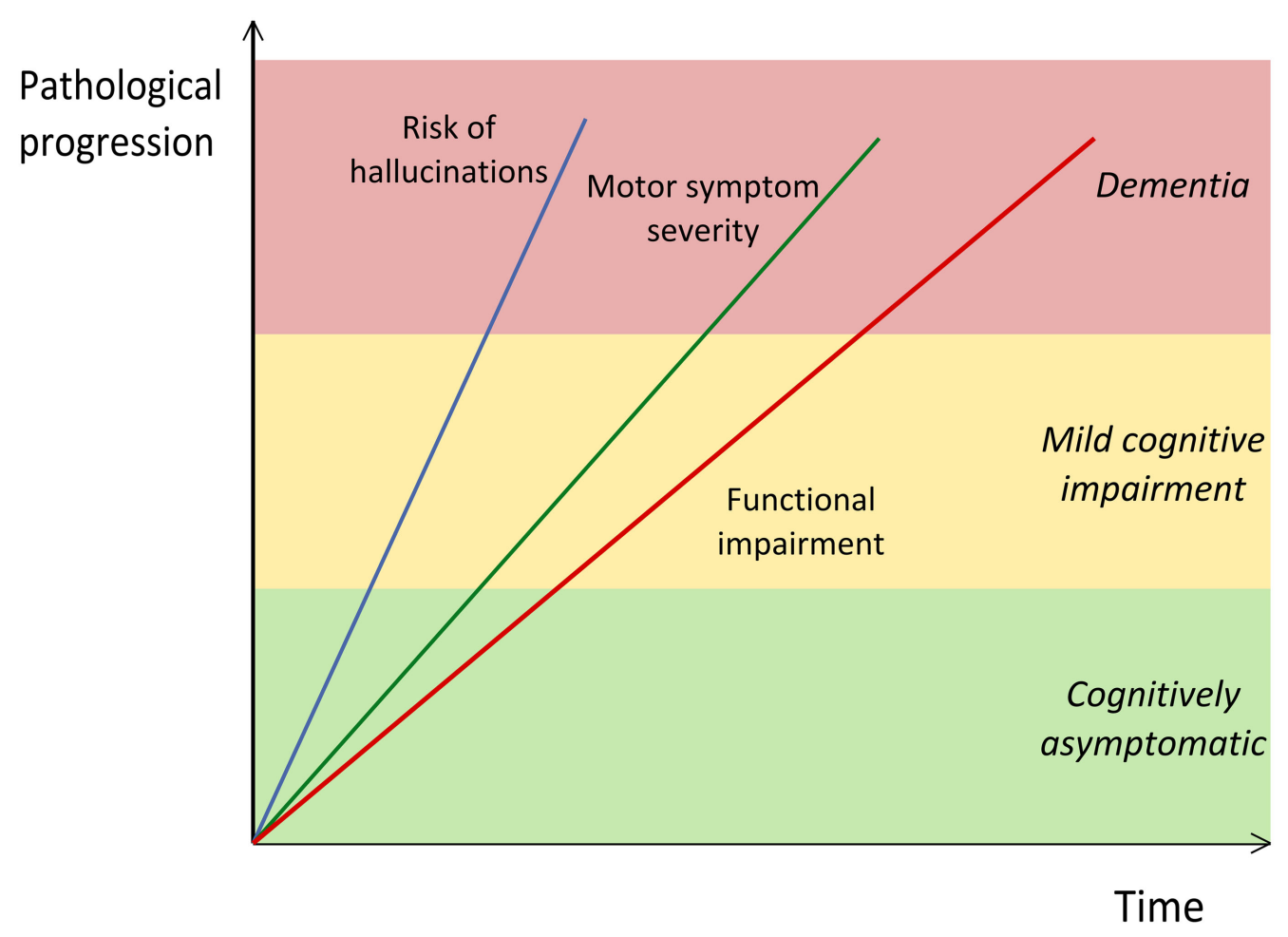

FIGURE 1 | schematic representation of the progression of PD patients until the stage of dementia. Functional impairment in PD is multifactorial (motor symptoms, cognitive decline, other non-motor symptoms). Please note that this graph is merely pictorial; it is not intended to represent proportions between variables nor is the progression linear, despite the drawing.
(Litvan et al., 2011). On the other hand, one wonders if drug therapy known to be effective in PD-D could be also of benefit at the stage of MCI, although this has not been formally studied in large trials. A contributing factor for this might be the lack of broadly accepted definitions and efficacy endpoints. In this regard, a very recent advance has been achieved, as the first set of consensus diagnostic criteria for PD-MCI have been proposed (Litvan et al., 2012).

\section{DIAGNOSTIC CRITERIA FOR MCI IN PARKINSON'S DISEASE}

The clinical validity of PD-MCI has found strong support in the published literature (Litvan et al., 2011). This concept has been formally accepted and used for several years, but only very recently has the first set of criteria for the formal diagnosis of PD-MCI been proposed (Litvan et al., 2012). A great contributor to a stagnant state regarding concrete definitions and criteria has been the scarcity of long term in-depth prospective studies that would allow better characterization of the phenotype of PD-MCI, to establish biomarker correlates, and to clearly define the progression and risk of dementia for PD-MCI patients. The MDS task force on PD-MCI has built this concept on the previous classic definitions of MCI and made the necessary adjustments regarding the specificities of $\mathrm{PD}$. The diagnosis of this condition requires a few key points. First of all, the diagnosis of PD should be well established. Then, cognitive decline must be reported by the patient or caregiver, or documented by the clinician. These are subsequently documented by means of formal cognitive assessment.
Lastly, cognitive impairment must not cause significant functional decline. Exclusion criteria have also been described and two levels of assessment and diagnostic certainty have been proposed (Litvan et al., 2012). The manuscript issued by this task force also proposes specific assessment tests and scales, which will hopefully expedite the homogenization and alliance of procedures throughout practice and research settings all over the world. However, no biomarkers could be recommended at this stage to incorporate the diagnostic criteria, as evidence is still scarce concerning this matter in the field of PD-D (Litvan et al., 2012).

\section{GENETICS AND COGNITIVE DECLINE IN PD HEREDITARY FORMS OF PARKINSON'S DISEASE AND COGNITION}

Ten to $15 \%$ of PD patients disclose a family history suggesting Mendelian inheritance, either autosomal dominant or recessive. These tend to be younger than the typical PD patients (Schrag and Schott, 2006; Tan and Jankovic, 2006). A number of levodopa responsive parkinsonian syndromes have been described and linked to a specific locus or gene, and 18 of these so far have been classified as PARK syndromes (Klein and Westenberger, 2012). While some of these represent true PD, others denote more complex phenotypes and different diseases (Gasser, 2007; Klein et al., 2009), which we will not address in this manuscript.

Several autosomal dominant forms of PD have been described, the most important being PARK1/PARK4 (gene SNCA, $\alpha$ synuclein) and PARK8 (gene LRRK2, leucine-rich repeat kinase 2). In PARK1/PARK4, which are infrequent forms of PD, symptoms 
usually emerge in the fourth or fifth decades, and patients display typical PD features, except that early prominent cognitive decline and dementia is a common event. Hence, the clinical picture may resemble DLB, although age at onset is much lower than in the classical cases. PARK1 and PARK4 are due to SNCA mutations and duplications/triplications, respectively (Polymeropoulos et al., 1997; Spira et al., 2001; Zarranz et al., 2004). PARK8 is probably the most common type of inherited PD. It has been reported that mutation frequency is about $40 \%$ in North African Arabs and Ashkenazi Jewish populations; high mutation frequency has also been reported in populations from southern Europe (Healy et al., 2008). The clinical picture resembles that of classical sporadic PD (Wszolek et al., 2004; Healy et al., 2008), and cognitive singularities have not been reported in this form of the disease, with a dementia prevalence of about 11\% (Kasten et al., 2010).

Three forms of autosomal recessive PD have been described: PARK2 (gene Parkin), PARK6 (gene PINK1, PTEN-induced putative kinase 1), and PARK7 (gene $D J-1$ ), here listed by decreasing order of frequency. The clinical pattern of PARK2 includes, in addition to typical PD features, a variety of symptoms such as hyperreflexia, prominent dystonia, sensory axonal neuropathy, increased sensitivity to levodopa induced dyskinesias, and psychosis (Abbas et al., 1999; Klein et al., 2000; Lücking et al., 2000; Gouider-Khouja et al., 2003; Khan et al., 2003; Deng et al., 2006; Wickremaratchi et al., 2009). Notably, non-motor symptoms seem to be less prevalent than in sporadic PD, except anxiety (Kägi et al., 2010). Therefore, cognitive decline is apparently less frequent, as compared to sporadic PD. Lewy bodies were absent in most patients that came to autopsy (Farrer et al., 2001; Gouider-Khouja et al., 2003). Age at onset of symptoms ranges from childhood to mid-fifties. It accounts for most PD cases under the age of 30 years. PARK6 and PARK7 share many common clinical features with PARK2, including early onset, excellent response to levodopa, and frequent levodopa induced dyskinesias, but psychiatric features may be more prominent in PARK6 (Valente et al., 2001, 2002, 2004; van Duijn et al., 2001; Abou-Sleiman et al., 2003; Dekker et al., 2003; Bonifati et al., 2005; Ibáñez et al., 2006; Leutenegger et al., 2006; Steinlechner et al., 2007; Kasten et al., 2010).

\section{GLUCOCEREBROSIDASE MUTATIONS: MORE THAN A SIMPLE RISK FACTOR FOR PD}

Interesting observations have been made in the last few years in families with members suffering from Gaucher's disease, an autosomal recessive disorder caused by homozygous mutations in the $G B A$ gene encoding the lysosomal enzyme glucocerebrosidase. Some years ago, heterozygous GBA mutations have been associated with a higher risk of PD (Aharon-Peretz et al., 2004; Sidransky et al., 2009), and data even suggested that these patients could have an increased risk for cognitive impairment. For instance, Brockmann et al. (2011) have found that non-motor symptoms, among them dementia, seem to be more prevalent in $G B A$-associated PD than in mutation non-carriers. Two pathogenic mutations (L444P and N470S) seem to be particularly prevalent, but others have been described (DePaolo et al., 2009; Neumann et al., 2009; Sidransky et al., 2009; Velayati et al., 2010). Interestingly, $G B A$ heterozygosity has also been associated with DLB, another synucleinopathy that shares clinical and pathological features with PD-D (Clark et al., 2009). Further clarifying these issues, SetóSalvia and coworkers have recently investigated GBA mutations in DLB and PD-D, by fully sequencing the gene in 225 PD patients, 17 pathologically proven DLB patients and 186 controls. Mutations were significantly more frequent in PD and DLB as compared to controls, and PD patients carrying GBA mutations were at higher risk of dementia, with an estimated adjusted odds ratio of 5.8, $p=0.001$ (Setó-Salvia et al., 2012). In fact, previous research has shown that GBA mutations are associated with more diffuse Lewy body neuropathology and greater neocortical involvement, which might explain the higher risk of cognitive decline in these PD patients (Neumann et al., 2009; Nishioka et al., 2011). Speculation has been brought to light about the putative association of other lysosomal disorders and parkinsonism (Shachar et al., 2011). For further details on this topic please refer to the manuscript by Almeida included in this Frontiers Research Topic (Almeida, 2012).

A word of caution should be given regarding $G B A$ testing in clinical practice. Current evidence clearly shows that heterozygous pathogenic mutations are a risk factor for PD and DLB. Thus, it has not been demonstrated that GBA mutations cause a monogenic form of PD or DLB. Therefore, similarly to what has been suggested for ApoE genotyping in AD (Goldman et al., 2011), testing for GBA mutations is not currently recommended with clinical diagnostic purposes. Similarly, testing cannot be recommended for the diagnosis of PD-D. Nonetheless, further scientific research should be encouraged regarding GBA in PD, as many aspects remain enigmatic.

\section{MICROTUBULE ASSOCIATED PROTEIN TAU AND COGNITIVE DECLINE IN PD}

Traditionally, microtubule associated protein tau (MAPT) gene mutations have been linked to autosomal dominant frontotemporal dementia, usually the behavioral variant, in particular the clinical forms also displaying parkinsonism (Galimberti and Scarpini, 2012). In addition, MAPT haplotype $\mathrm{H} 1$ has been associated with increased susceptibility for the development of PD (Elbaz et al., 2011; Trotta et al., 2012). In recent years, an interesting relationship has been acknowledged between MAPT haplotype $\mathrm{H} 1$ and clinical progression in $\mathrm{PD}$, specifically with regard to cognitive decline. Williams-Gray and coworkers have followed up their incident community PD CamPaIGN cohort and at 5 years $(n=162)$ have found that $17 \%$ of patients had developed dementia. In this study MAPT haplotype $\mathrm{H} 1$ was associated with accelerated cognitive decline, and was also a significant independent predictor of dementia, along with older age, and poor performance on semantic fluency and pentagon copy at diagnosis. The authors have conducted additional postmortem research using brain bank tissue, demonstrating that the $\mathrm{H} 1$ haplotype was also associated with $20 \%$ more deposit load of 4 repeat tau in Brodmann area 46 in Lewy body disease brains (PD or DLB), as compared to the $\mathrm{H} 2$ haplotype (Williams-Gray et al., 2009). The same working group subsequently assessed a representative group of $132 \mathrm{PD}$ patients from this cohort for up to 7.9 years from diagnosis, and tau haplotype $\mathrm{H} 1$ remained a strong risk factor for dementia at this time point (Evans et al., 2011). 
In a Spanish case-control study MAPT haplotypes were determined in 202 PD patients (48 of these with dementia), 41 patients with DLB (pathologically confirmed in 17), 164 patients with AD, and 374 controls. The authors have found that the haplotype $\mathrm{H} 1$ is significantly overrepresented in PD patients compared with controls and that the association was significantly stronger in PD-D than in non-demented PD patients, suggesting that MAPT H1 haplotype seems to be a strong risk factor for PD and for dementia in $\mathrm{PD}$ patients. In addition, no association could be found between any of the MAPT subhaplotypes and DLB or AD (Setó-Salvia et al., 2011).

The groups led by Andrew Siderowf has studied genotypic variants of apolipoprotein E (APOE), catechol-O-mehyltransferase (COMT), and MAPT, and whether these could be correlated with cognitive decline in PD in 212 clinically diagnosed patients followed up prospectively. APOE allele E4 was associated with faster decline, and MAPT and COMT could be correlated with performance in memory and attention, respectively, but not with the rate of general cognitive decline, as assessed with the Mattis Dementia Rating Scale version 2. Of note, $96 \%$ of patients in this cohort were assessed no later than at 3 years of follow-up (Morley et al., 2012).

\section{MANAGEMENT OF PD-D: GENERAL PRINCIPLES}

Parkinson's disease patients suffer significant decline in their QOL, due to motor symptoms, motor complications induced by progressive neurodegeneration and medication effects, and non-motor symptoms (Chaudhuri and Schapira, 2009; Lim et al., 2009; Tolosa et al., 2009; Calabresi et al., 2010; Hawkes et al., 2010; Savica et al., 2010; Schapira and Tolosa, 2010). Among these, dementia is a particularly important aspect, since it brings an additional and important burden of functional impairment associated with significant cognitive deterioration and further loss of QOL. The achievements in the last few decades regarding cognitive and behavioral issues in $\mathrm{PD}$ have been important scientific progresses (Weintraub and Burn, 2011), but research on clinical management is still scarce, particularly concerning randomized trials. There are no known disease modifying strategies in PD-D and every therapy here mentioned is currently seen as purely symptomatic.

Treating physicians should encourage an open dialog with the patient and family regarding the issue of cognitive decline in $\mathrm{PD}$, especially when symptoms are brought to light by the patient or the caregivers, or uncovered by the clinician. Subjective cognitive complains should be noted and delved in detail. Functional impairment due to cognitive deterioration should be searched for in the several daily life environments, such as at home or at work, by questioning the patient and significant others. Sensitive and user friendly screening scales like the Montreal Cognitive Assessment (MoCA; Dalrymple-Alford et al., 2010) can be used to quickly probe the severity of cognitive decline, although comprehensive neuropsychological assessment is the best way of defining the profile of impairment in detail. Associated neuropsychiatric symptoms should be searched for, so that they can be properly addressed.

Common sense advises that, as in other circumstances when cognitive decline is apparent, with or without concomitant functional impairment (i.e., dementia), treatable causes should be ruled out through suitable laboratory testing, such as hypothyroidism, vitamin B12 or folate deficiencies, renal, or liver failure, anemia, and exceptionally even VDRL or HIV antibodies in the appropriate setting (i.e., classical risk factors). Structural brain imaging should be considered in the context of new onset cognitive decline, including when brain vascular disease or atypical degenerative parkinsonian disorders are suspected; magnetic resonance imaging would be the modality of choice in this regard (Bohnen and Albin, 2011; Wattjes, 2011). Exceptionally, genetic testing can be considered, in carefully selected circumstances above mentioned in the text.

Marked cholinergic deficits can be found in the brain of PD-D patients (Kehagia et al., 2010), thus providing the rational basis for cholinesterase inhibitor therapy in this condition. Only one large randomized placebo-controlled trial has been published so far regarding the use of cholinesterase inhibitors in PD-D (Emre et al., 2004). Emre and collaborators have demonstrated that rivastigmine, a dual inhibitor of acetylcholinesterase and butyrylcholinesterase, brings modest but significant improvements in mild to moderate PD-D. As expected, gastrointestinal adverse events such as nausea and vomiting were more common in the group treated with rivastigmine. One wonders whether newer formulations (i.e., transdermal patch) would reduce gastrointestinal adverse events as compared to capsules, which has already been demonstrated for $\mathrm{AD}$ in the large randomized, controlled, doubleblind, double-dummy IDEAL trial (Winblad et al., 2007). Interestingly, visual hallucinations seem to predict better clinical outcomes under rivastigmine, as a mean statistically significant difference of 2.3 points on the Progressive Deterioration Scale has been documented in rivastigmine- versus placebo-treated patients without hallucinations at baseline, compared with a mean statistically significant difference of 5.3 points in patients with hallucinations at baseline (Emre et al., 2007b). Memantine has also been studied in PD-D, with two randomized double-blind placebo-controlled trials published thus far. One trial demonstrated marginal efficacy of memantine over placebo, regarding global clinical impression, and attention, whereas it failed to establish significant improvements in other secondary outcome measures (Aarsland et al., 2009). The second trial has shown clinical benefits of memantine on global clinical status and behavioral symptoms, but activities of daily living and caregiver burden did not improve (Emre et al., 2010). Both trials enrolled a mixed population of PD-D and DLB patients.

Behavioral or neuropsychiatric symptoms are common in PD$\mathrm{D}$ and often exceedingly disturbing for the patient and caregivers. They must be properly explored and managed. Thorough questioning of both the patient and caregiver is paramount in this regard. For instance, visual hallucinations are commonly uncovered in clinic during patient interview, which were previously not suspected at all by the astonished family.

No randomized controlled trials have been conducted regarding the treatment of depression in PD-D. Tricyclic antidepressants have been found superior to placebo in PD (Devos et al., 2008; Menza et al., 2009), but their anticholinergic effects advises against their use in PD-D, since the risk of additional cognitive deterioration and new onset confusion would be significantly increased (Labbate et al., 2009). Thus, depression in PD-D is usually treated with serotonin selective reuptake inhibitors (SSRIs), such as sertraline and citalopram, although evidence in favor of this practice 
is scarce (Wermuth et al., 1998; Leentjens et al., 2003; Weintraub et al., 2006; Devos et al., 2008). Noradrenaline and serotonin reuptake inhibitors like venlafaxine could be an alternative, but no trials have been published so far in this setting. Nonetheless, clinical practice has brought an overall positive experience with these drugs. Bupropion, that inhibits the reuptake of dopamine and noradrenaline, has been suggested by some to have a role in the treatment of depression in PD (Raskin and Durst, 2010; Zaluska and Dyduch, 2011), but controlled trials are also lacking. In any case, it appears that sedation and sexual dysfunction are lower with bupropion, when compared to SSRIs (Labbate et al., 2009). Recent research has found that pramipexole, a dopamine agonist widely used in the treatment of PD motor symptoms, improves depressive symptoms in PD (Barone et al., 2010), but the prescription should be carefully considered in PD-D due to the risk of visual hallucinations and confusion with this drug class.

Psychotic symptoms can be a challenging clinical problem in PD-D. Patients should be questioned about the content of their visual hallucinations and whether these are disturbing or not. They can be a source of significant anxiety and agitation or, on the other hand, be felt by the patient as friendly or at least non-threatening. At times the diagnosis of delirium is considered in PD-D, as patients may appear confuse and attention may become more volatile than usual. In this case, comorbid medical conditions should be searched for and treated, such as urinary tract infections, pneumonia, gastroenteritis, dehydration, or aggravated pre-existent disorders (e.g., renal or cardiac failure). Certain drugs seem prone to cause psychosis and confusional states, thus pharmacological therapy should be thoroughly reviewed and optimized. Antiparkinsonian drugs are often implicated - anticholinergics, selegiline, amantadine, dopamine agonists, and catechol-O-methyltransferase inhibitors should be discontinued, and lastly, a reduction in levodopa dosage should be considered. However, this approach is also not evidence-based. Antipsychotics should be used only as a last resort in PD-D. Atypical agents such as quetiapine can be used, despite the fact that trial results do not support this strategy (Ondo et al., 2005; Rabey et al., 2007; Shotbolt et al., 2009). Clozapine has been studied with a few positive results in PD patients (The Parkinson Study Group,

\section{REFERENCES}

Aarsland, D., Andersen, K., Larsen, J. P., Perry, R., Wentzel-Larsen, T., Lolk, A., and Kragh-Sørensen, P. (2004). The rate of cognitive decline in Parkinson disease. Arch. Neurol. 61, 1906-1911.

Aarsland, D., Ballard, C., Larsen, J. P., and McKeith, I. (2001a). A comparative study of psychiatric symptoms in dementia with Lewy bodies and Parkinson's disease with and without dementia. Int. J. Geriatr. Psychiatry 16, 528-536.

Aarsland, D., Cummings, J. L., and Larsen, J. P. (2001b). Neuropsychiatric differences between Parkinson's disease with dementia and Alzheimer's disease.

1999; Fernandez et al., 2004), but the hematological safety profile and significant muscarinic receptor affinity (Bymaster et al., 2003; Gareri et al., 2008) advise against its use in PD-D. Ondansetron, a 5-HT3 receptor antagonist used for the treatment of severe vomiting, especially in the setting of cancer chemotherapy, has also been tried as an antipsychotic agent, based on the rational that psychotic symptoms could be due to central serotoninergic overstimulation; Zoldan and coworkers conducted an open-label trial for 4-8 weeks, enrolling $16 \mathrm{PD}$ patients with psychosis (daily dose $12-24 \mathrm{mg}$ ). They have found that psychotic symptoms were significantly improved, with good tolerability and no repercussion on PD motor symptoms, levodopa efficacy, or general cognitive state (Zoldan et al., 1995). However, this line of research has not been followed subsequently by any other group, probably due to the high cost of the drug. Coping strategies to deal with hallucinations might be helpful for patients and caregivers (Diederich et al., 2009).

\section{CONCLUSION}

Parkinson's disease is much more than a motor disorder and a wide range of non-motor symptoms have been recognized along the years, especially in the last decades. Among them, cognitive decline, in a wide range of severity, is particularly important to recognize, due to the meaningful impact on the life of patients and caregivers, as well as the social and economic burden brought about by this condition. Expert consensus guidelines have been recently issued specifically for the diagnosis of $\mathrm{MCI}$ in $\mathrm{PD}$ and $\mathrm{PD}$ dementia. These have not been prospectively assessed so far, but might prove useful both in clinical and research settings, as clinical decisions and research methods will hopefully become more homogeneous. An array of cognitive and behavioral symptoms has been associated with PD-D, which should be properly characterized and managed, as patients benefit from specific interventions. Nevertheless, many clinical decisions and practices do not find solid support on evidence-based data, and rely on the older and less objective "experience-based medicine" practices. This is an important point to be addressed in the future, as multicenter randomized trials using recent consensus definitions should be considered in relevant clinical areas.

Kulisevsky, J., Burn, D., Barone, P., Pagonabarraga, J., Allcock, L., Santangelo, G., Foltynie, T., Janvin, C. Larsen, J. P., Barker, R. A., and Emre, M. (2010). Mild cognitive impairment in Parkinson disease: a multicenter pooled analysis. Neurology 75 1062-1069.

Aarsland, D., and Kurz, M. W. (2010). The epidemiology of dementia associated with Parkinson disease. J. Neurol. Sci. 289, 18-22.

Aarsland, D., Kvaloy, J. T., Anderson, K., Larsen, J. P., Tang, M. X., Lolk, A. Kragh-Sørensen, P., and Marder, K. (2007). The effect of age of onset of PD on risk of dementia. J. Neurol. 254, 38-45.
Aarsland, D., Larsen, J. P., Karlsen, K., Lim, N. G., and Tandberg, E. (1999). Mental symptoms in Parkinson's disease are important contributors to caregiver distress. Int. J. Geriatr. Psychiatry 14, 866-874.

Aarsland, D., Larsen, J. P., Tandberg, E., and Laake, K. (2000). Predictors of nursing home placement in Parkinson's disease: a population based, prospective study. J. Am. Geriatr. Soc. 48, 938-942.

Aarsland, D., Zaccai, J., and Brayne, C. (2005). A systematic review of prevalence studies of dementia in Parkinson's disease. Mov. Disord. 20, 1255-1263. 
Abbas, N., Lücking, C. B., Ricard, S., Dürr, A., Bonifati, V., De Michele, G., Bouley, S., Vaughan, J. R., Gasser, T., Marconi, R., Broussolle, E., BrefelCourbon, C., Harhangi, B. S., Oostra, B. A., Fabrizio, E., Böhme, G. A., Pradier, L., Wood, N. W., Filla, A., Meco, G., Denefle, P., Agid, Y., and Brice, A. (1999). A wide variety of mutations in the parkin gene are responsible for autosomal recessive parkinsonism in Europe. Hum. Mol. Genet. 8, 567-574.

Abou-Sleiman, P. M., Healy, D. G., Quinn, N., Lees, A. J., and Wood, N. W. (2003). The role of pathogenic DJ-1 mutations in Parkinson's disease. Ann. Neurol. 54, 283-286.

Aharon-Peretz, J., Rosenbaum, H., and Gershoni-Baruch, R. (2004). Mutations in the glucocerebrosidase gene and Parkinson's disease in Ashkenazi Jews. N. Engl. J. Med. 351, 1972-1977.

Allan, L. M., Ballard, C. G., Allen, J., Murray, A., Davidson, A. W., McKeith, I. G., and Kenny, R. A. (2007). Autonomic dysfunction in dementia. J. Neurol. Neurosurg. Psychiatr. 78, 671-677.

Almeida, M. R. (2012). Glucocerebrosidase involvement in Parkinson disease and other synucleinopathies. Front. Neurol. 3:65. doi:10.3389/fneur.2012.00065

Alves, L., Correia, A. S. A., Miguel, R., Alegria, P., and Bugalho, P. (2012). Alzheimer's disease: a clinical practice-oriented review. Front. Neurol. 3:63. doi:10.3389/fneur.2012.00063

American Psychiatric Association. (1994). Diagnostic, and Statistical Manual of Mental Disorders, DSM$I V$, 4th Edn. Arlington: American Psychiatric Press Inc.

Ballard, C. G., Aarsland, D., McKeith, I., O’Brien, J., Gray, A., Cormack, F., Burn, D., Cassidy, T., Starfeldt, R., Larsen, J. P., Brown, R., and Tovee, M. (2002). Fluctuations in attention in PD dementia vs DLB with parkinsonism. Neurology 59, 1714-1720.

Barone, P., Aarsland, D., Burn, D., Emre, M., Kulisevsky, J., and Weintraub, D. (2011). Cognitive impairment in nondemented Parkinson's disease. Mov. Disord. 26, 2483-2495.

Barone, P., Poewe, W., Albrecht, S., Debieuvre, C., Massey, D., Rascol, O., Tolosa, E., and Weintraub, D. (2010). Pramipexole for the treatment of depressive symptoms in patients with Parkinson's disease: a randomised, double-blind, placebocontrolled trial. Lancet Neurol. 9, 573-580.
Barton, B., Grabli, D., Bernard, B., Czernecki, V., Goldman, J. G., Stebbins, G., Dubois, B., and Goetz, C. G. (2012). Clinical validation of movement disorder societyrecommended diagnostic criteria for Parkinson's disease with dementia. Mov. Disord. 27, 248-253.

Benoit, M., Robert, P. H., Staccini, P., Brocker, P., Guerin, O., Lechowski, L., Vellas, B., and REAL.FR Group. (2005). One-year longitudinal evaluation of neuropsychiatric symptoms in Alzheimer's disease. The REAL.FR Study. J. Nutr. Health Aging 9, 95-99.

Boeve, B. F., Silber, M. H., Saper, C. B., Ferman, T. J., Dickson, D. W., Parisi, J. E., Benarroch, E. E., Ahlskog, J. E., Smith, G. E., Caselli, R. C., TippmanPeikert, M., Olson, E. J., Lin, S. C., Young, T., Wszolek, Z., Schenck, C. H., Mahowald, M. W., Castillo, P. R., Del Tredici, K., and Braak, H. (2009). Pathophysiology of REM sleep behaviour disorder and relevance to neurodegenerative disease. Brain 130, 2770-2788.

Bohnen, N. I., and Albin, R. L. (2011). White matter lesions in Parkinson disease. Nat. Rev. Neurol. 7, 229-236.

Bonelli, R. M., and Cummings, J. L. (2008). Frontal-subcortical dementias. Neurologist 14, 100-107.

Bonelli, S. B., Ransmayr, G., Steffelbauer, M., Lukas, T., Lampl, C., and Deibl, M. (2004). L-dopa responsiveness in dementia with Lewy bodies, Parkinson disease with and without dementia. Neurology 63, 376-378.

Bonifati, V., Rohé, C. F., Breedveld, G. J., Fabrizio, E., De Mari, M., Tassorelli, C., Tavella, A., Marconi, R., Nicholl, D. J., Chien, H. F., Fincati, E., Abbruzzese, G., Marini, P., De Gaetano, A., Horstink, M. W., MaatKievit, J. A., Sampaio, C., Antonini, A., Stocchi, F., Montagna, P., Toni, V., Guidi, M., Dalla Libera, A., Tinazzi, M., De Pandis, F., Fabbrini, G., Goldwurm, S., de Klein, A., Barbosa, E., Lopiano, L., Martignoni, E., Lamberti, P., Vanacore, N., Meco, G., Oostra, B. A., and Italian Parkinson Genetics Network. (2005). Earlyonset parkinsonism associated with PINK1 mutations: frequency, genotypes, and phenotypes. Neurology 65, 87-95.

Braak, H., Del Tredici, K., Rüb, U., de Vos, R. A., Jansen Steur, E. N., and Braak, E. (2003). Staging of brain pathology related to sporadic Parkinson's disease. Neurobiol. Aging 24, 197-211.

Brockmann, K., Srulijes, K., Hauser, A. K., Schulte, C., Csoti, I., Gasser, T., and Berg, D. (2011). GBA-associated PD presents with nonmotor characteristics. Neurology 77, 276-280.

Bronnick, K., Aarsland, D., and Larsen, J. P. (2005). Neuropsychiatric disturbances in Parkinson's disease clusters in five groups with different prevalence of dementia. Acta Psychiatr. Scand. 112, 201-207.

Bronnick, K., Emre, M., Lane, R., Tekin, S., and Aarsland, D. (2007). Profile of cognitive impairment in dementia associated with Parkinson's disease compared with Alzheimer's disease. J. Neurol. Neurosurg. Psychiatr. 78, 1064-1068.

Burn, D. J., Rowan, E. N., Allan, L. M., Molloy, S., O’Brien, J. Y., and McKeith, I. J. (2006). Motor subtype and cognitive decline in Parkinson's disease, Parkinson's disease with dementia, and dementia with Lewy bodies. J. Neurol. Neurosurg. Psychiatr. 77, 585-589.

Bymaster, F. P., Felder, C. C., Tzavara, E. Nomikos, G. G., Calligaro, D. O., and Mckinzie, D. L. (2003). Muscarinic mechanisms of antipsychotic atypicality. Prog. Neuropsychopharmacol. Biol. Psychiatry 27, 1125-1143.

Cahn-Weiner, D. A., Grace, J., Ott, B. R., Fernandez, H. H., and Friedman J. H. (2002). Cognitive and behavioral features discriminate between Alzheimer's and Parkinson's disease. Neuropsychiatry Neuropsychol. Behav. Neurol. 15, 79-87.

Cahn-Weiner, D. A., Williams, K., Grace, J., Tremont, G., Westervelt, H., and Stern R. A. (2003). Discrimination of dementia with lewy bodies from Alzheimer disease and Parkinson disease using the clock drawing test. Cogn. Behav. Neurol. 16, 85-92.

Calabresi, P., Di Filippo, M., Ghiglieri, V., Tambasco, N., and Picconi, B. (2010). Levodopa-induced dyskinesias in patients with Parkinson's disease: filling the bench-to-bedside gap. Lancet Neurol. 9, 1106-1117.

Caparros-Lefebvre, D., Pecheux, N., and Petit, V. (1995). Which factors predict cognitive decline in Parkinson's disease? J. Neurol. Neurosurg. Psychiatr. 58, 51-55.

Caviness, J. N., Driver-Dunckley, E., Connor, D. J., Sabbagh, M. N., Hentz, J. G., Noble, B., Evidente, V. G. H., Shill, H., and Adler, C. H. (2007a). Defining mild cognitive impairment in Parkinson's disease. Mov. Disord. $22,1272-1277$.

Caviness, J. N., Hentz, J. G., Evidente, V. G., Driver-Dunckley, E., Samanta, J., Mahant, P., Connor, D. J., Sabbagh, M. N., Shill, H. A., and Adler, C. H. (2007b). Both early and late cognitive dysfunction affects the electroencephalogram in Parkinson's disease. Parkinsonism Relat. Disord. 13, 348-354.

Chaudhuri, K. R., and Schapira, A. H. V. (2009). Non-motor symptoms of Parkinson's disease: dopaminergic pathophysiology and treatment. Lancet Neurol. 8, 464-474.

Clark, L. N., Kartsaklis, L. A., Wolf Gilbert, R., Dorado, B., Ross, B. M., Kisselev, S., Verbitsky, M., MejiaSantana, H., Cote, L. J., Andrews, H., Vonsattel, J. P., Fahn, S., Mayeux, R., Honig, L. S., and Marder, K. (2009). Association of glucocerebrosidase mutations with dementia with Lewy bodies. Arch. Neurol. 66, 578-583.

Cummings, J. L. (1988). The dementias of Parkinson's disease: prevalence, characteristics, neurobiology, and comparison with dementia of the Alzheimer type. Eur. Neurol. 28(Suppl. 1), 15-23.

Dalrymple-Alford, J. C., MacAskill, M. R., Nakas, C. T., Livingston, L., Graham, C., Crucian, G. P., Melzer, T. R., Kirwan, J., Keenan, R., Wells, S., Porter, R. J., Watts, R., and Anderson, T. J. (2010). The MoCA: wellsuited screen for cognitive impairment in Parkinson disease. Neurology 75, 1717-1725.

Darvesh, S., and Freedman, M. (1996). Subcortical dementia: a neurobehavioral approach. Brain Cogn. 31, 230-249.

de Lau, L. M., Schipper, C. M., Hofman, A., Koudstaal, P. J., and Breteler, M. M. (2005). Prognosis of Parkinson disease: risk of dementia and mortality: the Rotterdam Study. Arch. Neurol. 62, 1265-1269.

Dekker, M., Bonifati, V., van Swieten, J., Leenders, N., Galjaard, R. J., Snijders, P., Horstink, M., Heutink, P., Oostra, B., and van Duijn, C. (2003). Clinical features and neuroimaging of PARK7-linked parkinsonism. Mov. Disord. 18, 751-757.

Deng, H., Le, W., Guo, Y., Hunter, C. B., Xie, W., Huang, M., and Jankovic, J. (2006). Genetic analysis of LRRK2 mutations in patients with Parkinson disease. J. Neurol. Sci. 251, 102-106.

DePaolo, J., Goker-Alpan, O., Samaddar, T., Lopez, G., and Sidransky, E. (2009). The association between mutations in the lysosomal protein glucocerebrosidase and parkinsonism. Mov. Disord. 24, 1571-1578.

Devos, D., Dujardin, K., Poirot, I., Moreau, C., Cottencin, O., Thomas, P., Destée, A., Bordet, R., and Defebvre, L. (2008). Comparison of desipramine and citalopram treatments for depression in Parkinson's 
disease: a double-blind, randomized, placebo-controlled study. Mov. Disord. 23, 850-857.

Diederich, N. J., Fénelon, G., Stebbins, G., and Goetz, C. G. (2009). Hallucinations in Parkinson disease. Nat. Rev. Neurol. 5, 331-342.

Domellöf, M. E., Elgh, E., and Forsgren, L. (2011). The relation between cognition and motor dysfunction in drug-naive newly diagnosed patients with Parkinson's disease. Mov. Disord. 26, 2183-2189.

Dubois, B., Burn, D., Goetz, C., Aarsland, D., Brown, R. G., Broe, G. A., Dickson, D., Duyckaerts, C., Cummings, J., Gauthier, S., Korczyn, A., Lees, A., Levy, R., Litvan, I., Mizuno, Y., McKeith, I. G., Olanow, C. W., Poewe, W., Sampaio, C., Tolosa, E., and Emre, M. (2007). Diagnostic procedures for Parkinson's disease dementia: recommendations from the movement disorder society task force. Mov. Disord. 22, 2314-2324.

Dujardin, K., Dubois, B., Tison, F., Durif, F., Bourdeix, I., Péré, J.-J., and Duhamel, A. (2010). Parkinson's disease dementia can be easily detected in routine clinical practice. Mov. Disord. 25, 2769-2776.

Elbaz, A., Ross, O. A., Ioannidis, J. P. A., Soto-Ortolaza, A. I., Moisan, F., and Aasly, J., Annesi, G., Bozi, M., Brighina, L., Chartier-Harlin, M.-C., Destée, A., Ferrarese, C., Ferraris, A., Gibson, J. M., Gispert, S., Hadjigeorgiou, G. M., Jasinska-Myga, B., Klein, C., Krüger, R., Lambert, J. C., Lohmann, K., van de Loo, S., Loriot, M. A., Lynch, T., Mellick, G. D., Mutez, E., Nilsson, C., Opala, G., Puschmann, A., Quattrone, A., Sharma, M., Silburn, P. A., Stefanis, L., Uitti, R. J., Valente, E. M., Vilariño-Güell, C., Wirdefeldt, K., Wszolek, Z. K., Xiromerisiou, G., Maraganore, D. M., Farrer, M. J., and Genetic Epidemiology of Parkinson's Disease (GEO-PD) Consortium. (2011). Independent and joint effects of the MAPT and SNCA genes in Parkinson disease. Ann. Neurol. 69, 778-792.

Elizan, T. S., Sroka, H., Maker, H., Smith, H., and Yahr, M. D. (1986). Dementia in idiopathic Parkinson's disease: variables associated with its occurrence in 203 patients. J. Neural Transm. 65, 285-302.

Emre, M. (2010). "General features, mode of onset and course of dementia in Parkinson's disease," in Cognitive Impairment and Dementia in Parkinson's Disease, ed. M. Emre (Oxford: Oxford University Press), 15-22.
Emre, M., Aarsland, D., Albanese, A., Byrne, E. J., Deuschl, G., De Deyn, P. P., Durif, F., Kulisevsky, J., van Laar, T., Lees, A., Poewe, W., Robillard, A., Rosa, M. M., Wolters, E., Quarg, P., Tekin, S., and Lane, R. (2004). Rivastigmine for dementia associated with Parkinson's disease. N. Engl. J. Med. 351, 2509-2518.

Emre, M., Aarsland, D., Brown, R., Burn, D. J., Duyckaerts, C., Mizuno, Y., Broe, G. A., Cummings, J., Dickson, D. W., Gauthier, S., Goldman, J., Goetz, C., Korczyn, A., Lees, A., Levy, R., Litvan, I., McKeith, I., Olanow, W., Poewe, W., Quinn, N., Sampaio, C., Tolosa, E., and Dubois, B. (2007a). Clinical diagnostic criteria for dementia associated with Parkinson's disease. Mov. Disord. 22, 1689-1707.

Emre, M., Cummings, J. L., and Lane, R. M. (2007b). Rivastigmine in dementia associated with Parkinson's disease and Alzheimer's disease: similarities and differences. J. Alzheimers Dis. 11, 509-519.

Emre, M., Tsolaki, M., Bonuccelli, U., Destée, A., Tolosa, E., Kutzelnigg, A., Ceballos-Baumann, A., Zdravkovic, S., Bladström, A., Jones, R., and 11018 Study Investigators. (2010). Memantine for patients with Parkinson's disease dementia or dementia with Lewy bodies: a randomised, double-blind, placebocontrolled trial. Lancet Neurol. 9, 969-977.

Engelborghs, S., Maertens, K., Nagels, G., Vloeberghs, E., Mariën, P., Symons, A., Ketels, V., Estercam, S., Somers, N., and De Deyn, P. P. (2005). Neuropsychiatric symptoms of dementia: cross-sectional analysis from a prospective, longitudinal Belgian study. Int. J. Geriatr. Psychiatry 20, 1028-1037.

Evans, J. R., Mason, S. L., WilliamsGray, C. H., Foltynie, T., Brayne, C., Robbins, T. W., and Barker, R. A. (2011). The natural history of treated Parkinson's disease in an incident, community based cohort. J. Neurol. Neurosurg. Psychiatr. 82, 1112-1118.

Farrer, M., Chan, P., Chen, R., Tan, L., Lincoln, S., Hernandez, D., Forno, L., Gwinn-Hardy, K., Petrucelli, L., Hussey, J., Singleton, A., Tanner, C., Hardy, J., and Langston, J. W. (2001). Lewy bodies and parkinsonism in families with parkin mutations. Ann. Neurol. 50, 293-300.

Fenelon, G., Mahieux, F., Huon, R., and Ziegler, M. (2000). Hallucinations in Parkinson's disease: prevalence, phenomenology and risk factors. Brain $123,733-745$.
Fernandez, H. H., Donnelly, E. M. and Friedman, J. H. (2004). Longterm outcome of clozapine use for psychosis in parkinsonian patients. Mov. Disord. 19, 831-833.

Ferrini-Strambi, L., Di Gioia, M. R. Castronovo, V., Oldani, A., Zucconi, M., and Cappa, S. F. (2004). Neuropsychological assessment in idiopathic REM sleep behavior disorder. Neurology 61, 41-45.

Foltynie, T., Brayne, C. E. G., Robbins, T. W., and Barker, R. A. (2004). The cognitive ability of an incident cohort of Parkinson's patients in the UK. The CamPaIGN study. Brain 127, 1-11.

Frank, E. M., McDade, H. L., and Scott, W. K. (1996). Naming in dementia secondary to Parkinson's, Huntington's, and Alzheimer's diseases. J. Commun. Disord. 29, 183-197.

Frauscher, B., Iranzo, A., Högl, B. Casanova-Molla, J., and Salamero, M., Gschliesser, V., Tolosa, E. Poewe, W., Santamaria, J., SINBAR (Sleep Innsbruck Barcelona group). (2008). Quantification of electromyographic activity during REM sleep in multiple muscles in REM sleep behavior disorder. Sleep 31, 724-731.

Gagnon, J. F., Vendette, M., Postuma, R. B., Desjardins, C., MassicotteMarquez, J., Panisset, M., and Montplaisir, J. (2009). Mild cognitive impairment in rapid eye movement sleep behavior disorder and Parkinson's disease. Ann. Neurol. 66, 39-47.

Galimberti, D., and Scarpini, E. (2012). Genetics of frontotemporal lobar degeneration. Front. Neurol. 3:52. doi:10.3389/fneur.2012.00052

Gareri, P., De Fazio, P., Russo, E., Marigliano, N., De Fazio, S., and De Sarro, G. (2008). The safety of clozapine in the elderly. Expert Opin. Drug Saf. 7, 525-538.

Gasser, T. (2007). Update on the genetics of Parkinson's disease. Mov. Disord. 22(Suppl. 17), S343-S350.

Giladin, N., Treves, T. A., Paleacu, D., Shabtai, H., Orlov, Y., Kandinov, B., Simon, E. S., and Korczyn, A. D. (2000). Risk factors for dementia and depression and psychosis in long standing Parkinson's disease. $J$. Neural Transm. 107, 59-71.

Gjerstad, M. D., Aarsland, D., and Larsen, J. P. (2002). Development of daytime somnolence over time in Parkinson's disease. Neurology 18, 1544-1546.

Goetz, C. G. (2011). The history of Parkinson's disease: early clinical descriptions and neurological therapies. Cold Spring Harb. Perspect. Med. 1, a008862.
Goetz, C. G., Emre, M., and Dubois, B. (2008). Parkinson's disease dementia: definitions, guidelines, and research perspectives in diagnosis. Ann. Neurol. 64, S81-S92.

Goldman, J. S., Hahn, S. E., Catania, J. W., LaRusse-Eckert, S., Butson, M. B., Rumbaugh, M., Strecker, M. N., Roberts, J. S., Burke, W., Mayeux, R., and Bird, T., American College of Medical Genetics and the National Society of Genetic Counselors. (2011). Genetic counseling and testing for Alzheimer disease: joint practice guidelines of the American College of Medical Genetics and the National Society of Genetic Counselors. Genet. Med. 13, 597-605.

Gouider-Khouja, N., Larnaout, A., Amouri, R., Sfar, S., Belal, S., Ben Hamida, C., Ben Hamida, M., Hattori, N., Mizuno, Y., and Hentati, F. (2003). Autosomal recessive parkinsonism linked to parkin gene in a Tunisian family. Clinical, genetic and pathological study. Parkinsonism Relat. Disord. 9, 247-251.

Hanes, K. R., Pantelis, C., Andrewes, D. G., and Chiu, E. (1996). Brief report: bradyphrenia in Parkinson's disease, Huntington's disease, and schizophrenia. Cogn. Neuropsychiatry 1, 165-170.

Hawkes, C. H., Del Tredici, K., and Braak, H. (2010). A timeline for Parkinson's disease. Parkinsonism Relat. Disord. 16, 79-84.

Healy, D. G., Falchi, M., O'Sullivan, S. S., Bonifati, V., Durr, A., Bressman, S., Brice, A., Aasly, J., Zabetian, C. P., Goldwurm, S., Ferreira, J. J., Tolosa, E., Kay, D. M., Klein, C., Williams, D. R., Marras, C., Lang, A. E., Wszolek, Z. K., Berciano, J., Schapira, A. H., Lynch, T., Bhatia, K. P., Gasser, T., Lees, A. J., Wood, N. W., and International LRRK2 Consortium. (2008). Phenotype, genotype, and worldwide genetic penetrance of LRRK2-associated Parkinson's disease: a case-control study. Lancet Neurol. 7, 583-590.

Hely, M. A., Morris, J. G., Reid, W. G., O'Sullivan, D. J., Williamson, P. M., Rail, D., Broe, G. A., and Margrie, S. (1994). The Sydney Multicentre Study of Parkinson's disease: a randomised, prospective five year study comparing low dose bromocriptine with low dose levodopa-carbidopa. J. Neurol. Neurosurg. Psychiatr. 57, 903-910.

Hely, M. A., Morris, J. G., Reid, W. G., and Trafficante, R. (2005). Sydney multicenter study of Parkinson's disease: non-L-dopa-responsive 
problems dominate at 15 years. Mov. Disord. 20, 190-199.

Hely, M. A., Reid, W. G., Adena, M. A., Halliday, G. M., and Morris, J. G. (2008). The Sydney multicenter study of Parkinson's disease: the inevitability of dementia at 20 years. Mov. Disord. 23, 837-844.

Henry, J. D., and Crawford, J. R. (2004). Verbal fluency deficits in Parkinson's disease: a meta-analysis. J. Int. Neuropsychol. Soc. 10, 608-622.

Higginson, C. I., Wheelock, V. L., Carroll, K. E., and Sigvardt, K. A. (2005). Recognition memory in Parkinson's disease with and without dementia: evidence inconsistent with the retrieval deficit hypothesis. J. Clin. Exp. Neuropsychol. 27, 516-528.

Hirono, N., Mori, E., Tanimukai, S., Kazui, H., Hashimoto, M., Hanihara, T., and Imamura, T. (1999). Distinctive neurobehavioral features among neurodegenerative dementias. J. Neuropsychiatry Clin. Neurosci. 11, 498-503.

Hobson, P., Meara, J., and IshiharaPaul, L. (2010). The estimated life expectancy in a community cohort of Parkinson's disease patients with and without dementia, compared with the UK population. J. Neurol. Neurosurg. Psychiatr. 81, 1093-1098.

Hughes, T. A., Ross, H. F., Musa, S., Bhattacherjee, S., Nathan, R. N., Mindham, R. H., and Spokes, E. G. (2000). A 10-year study of the incidence of and factors predicting dementia in Parkinson's disease. Neurology 54, 1596-1602.

Ibáñez, P., Lesage, S., Lohmann, E., Thobois, S., De Michele, G., Borg, M., Agid, Y., Dürr, A., Brice, A., and French Parkinson's Disease Genetics Study Group. (2006). Mutational analysis of the PINK1 gene in earlyonset parkinsonism in Europe and North Africa. Brain 129, 686-694.

Idiaquez, J., Benarroch, E. E., Rosales, H., Milla, P., and Ríos, L. (2007). Autonomic and cognitive dysfunction in Parkinson's disease. Clin. Auton. Res. 17, 93-98.

Iranzo, A. (2011). Sleep-wake changes in the premotor stage of Parkinson disease. J. Neurol. Sci. 310, 283-285.

Iranzo, A., Molinuevo, J. L., Santamaría, J., Serradell, M., Martí, M. J., Valldeoriola, F., and Tolosa, E. (2006). Rapid-eye-movement sleep behavior disorder as an early marker for a neurodegenerative disease: a descriptive study. Lancet Neurol. 5, 572-577.

Iranzo, A., Santamaría, J., Rye, D. B., Valldeoriola, F., Martí, M. J., Muñoz, E., Vilaseca, I., and Tolosa, E. (2005). Characteristics of idiopathic REM sleep behavior disorder and that associated with MSA and PD. Neurology 65, 247-252.

Janvin, C. C., Larsen, J. P., Salmon, D. P., Galasko, D., Hugdahl, K., and Aarsland, D. (2006). Cognitive profiles of individual patients with Parkinson's disease and dementia: comparison with dementia with Lewy bodies and Alzheimer's disease. Mov. Disord. 21, 337-342.

Jeannerod, M., and Jacob, P. (2005). Visual cognition: a new look at the two-visual systems model. $\mathrm{Neu}$ ropsychologia 43, 301-312.

Joyce, J. N., Ryoo, H. L., Beach, T. B., Caviness, J. N., Stacy, M., Gurevich, E. V., Reiser, M., and Adler, C. H. (2002). Loss of response to levodopa in Parkinson's disease and cooccurrence with dementia: role of D3 and not D2 receptors. Brain Res. 955, 138-152.

Kägi, G., Klein, C., Wood, N. W., Schneider, S. A., Pramstaller, P. P., Tadic, V., Quinn, N. P., van de Warrenburg, B. P., and Bhatia K. P. (2010). Nonmotor symptoms in Parkin generelated parkinsonism. Mov. Disord. 25, 1279-1284.

Kai, T., Asai, T., Sakuma, K., Koeda, T., and Nakashima, K. (2005). Quantitative electroencephalogram analysis in dementia with Lewy Bodies and Alzheimer disease. J. Neurol. Sci. 237, 89-95.

Kasten, M., Kertelge, L., Brüggemann, N., van der Vegt, J., Schmidt, A. Tadic, V., Buhmann, C., Steinlechner, S., Behrens, M. I., Ramirez, A., Binkofski, F., Siebner, H., Raspe, H., Hagenah, J., Lencer, R., and Klein, C. (2010). Nonmotor symptoms in genetic Parkinson disease. Arch. Neurol. 67, 670-676.

Kehagia, A. A., Barker, R. A., and Robbins, T. W. (2010). Neuropsychological and clinical heterogeneity of cognitive impairment and dementia in patients with Parkinson's disease. Lancet Neurol. 9, 1200-1213.

Kertesz, A. (2003). Pick complex: an integrative approach to frontotemporal dementia: primary progressive aphasia, corticobasal degeneration, and progressive supranuclear palsy. Neurologist 9, 311-317.

Khan, N. L., Graham, E., Critchley, P., Schrag, A. E., Wood, N. W., Lees, A. J., Bhatia, K. P., and Quinn, N. (2003). Parkin disease: a phenotypic study of a large case series. Brain 126, 1279-1292.

Klein, C., Pramstaller, P. P., Kis, B., Page, C. C., Kann, M., Leung, J., Woodward, H., Castellan, C. C., Scherer, M., Vieregge, P., Breakefield, X. O., Kramer, P. L., and Ozelius, L. J.
(2000). Parkin deletions in a family with adult-onset, tremor-dominant parkinsonism: expanding the phenotype. Ann. Neurol. 48, 65-71.

Klein, C., Schneider, S. A., and Lang, A. E. (2009). Hereditary parkinsonism: Parkinson disease look alikes - an algorithm for clinicians to "PARK" genes and beyond. Mov. Disord. 24, 2042-2058.

Klein, C., and Westenberger, A. (2012). Genetics of Parkinson's disease. Cold Spring Harb. Perspect. Med. 2, a008888.

Kramer, J. H., and Duffy, J. M. (1996). Aphasia, apraxia, and agnosia in the diagnosis of dementia. Dementia 7, 23-26.

Kudlicka, A., Clare, L., and Hindle, J. V. (2011). Executive functions in Parkinson's disease: systematic review and meta-analysis. Mov. Disord. 26, 2305-2315.

Labbate, L. A., Fava, M., and Rosenbaum, J. F. and Arana G. W. (2009). Handbook of Psychiatric Drug Ther$a p y, 6$ th Edn. Philadelphia: Lippincott Williams \& Wilkins.

Leentjens, A. F., Vreeling, F. W., Luijckx, G. J., and Verhey, F. R. (2003). SSRIs in the treatment of depression in Parkinson's disease. Int. J. Geriatr. Psychiatry 18, 552-554.

Leutenegger, A. L., Salih, M. A., Ibáñez, P., Mukhtar, M. M., Lesage, S., Arabi, A., Lohmann, E., Dürr, A., Ahmed, A. E., and Brice, A. (2006). Juvenile-onset parkinsonism as a result of the first mutation in the adenosine triphosphate orientation domain of PINK1. Arch. Neurol. 63 1257-1261.

Levy, G., Tang, M. X., Louis, E. D., Côté, L. J., Alfaro, B., Mejia, H., Stern, Y., and Marder, K. (2002). The association of incident dementia with mortality in PD. Neurology 59, 1708-1713.

Lim, S. Y., Fox, S. H., and Lang, A. E. (2009). Overview of the extranigral aspects of Parkinson disease. Arch. Neurol. 66, 167-172.

Litvan, I., Aarsland, D., Adler, C. H., Goldman, J. G., Kulisevsky, J., Mollenhauer, B., Rodriguez-Oroz, M. C., Tröster, A. I., and Weintraub, D. (2011). MDS Task Force on mild cognitive impairment in Parkinson's disease: critical review of PD-MCI. Mov. Disord. 15, 1814-1824.

Litvan, I., Goldman, J. G., Tröster, A. I., Schmand, B. A., Weintraub, D., Petersen, R. C., Mollenhauer, B. Adler, C. H., Marder, K., WilliamsGray, C. H., Aarsland, D., Kulisevsky, J., Rodriguez-Oroz, M. C., Burn, D. J., Barker, R. A., and Emre, M. (2012).
Diagnostic criteria for mild cognitive impairment in Parkinson's disease: Movement Disorder Society Task Force guidelines. Mov. Disord. 24, 489-495.

Lücking, C. B., Dürr, A., Bonifati, V., Vaughan, J., De Michele, G. Gasser, T., Harhangi, B. S., Meco, G., Denèfle, P., Wood, N. W., Agid, Y., Brice, A., French Parkinson's Disease Genetics Study Group, and European Consortium on Genetic Susceptibility in Parkinson's Disease. (2000). Association between earlyonset Parkinson's disease and mutations in the parkin gene. N. Engl. J. Med. 342, 1560-1567.

Mamikonyan, E., Moberg, P. J., Siderowf, A., Duda, J. E., Have, T. T., Hurtig, H. I., Stern, M. B., and Weintraub, D. (2009). Mild cognitive impairment is common in Parkinson's disease patients with normal Mini-Mental State Examination (MMSE) scores. Parkinsonism Relat. Disord. 15, 226-231.

Martinez-Martin, P., Falup-Pecurariu, C., Rodriguez-Blazquez, C. Serrano-Dueñas, M., Carod Artal, F. J., Rojo Abuin, J. M., and Aarsland, D. (2011). Dementia associated with Parkinson's disease: applying the Movement Disorder Society Task Force criteria. Parkinsonism Relat. Disord. 17, 621-624.

Massano, J., and Bhatia, K. P. (2012). Clinical approach to Parkinson's disease: features, diagnosis, and principles of management. Cold Spring Harb. Perspect. Med. doi:10.1101/cshperspect.000870. (in press).

Massano, J., and Garrett, C. (2012). Deep brain stimulation and cognitive decline in Parkinson's disease: a clinical review. Front. Neurol. 3:66. doi:10.3389/fneur.2012.00066

McKeith, I. (2005). Dementia with Lewy bodies and Parkinson's disease with dementia: where two worlds collide. Pract. Neurol. 7, 374-382.

McKeith, I. G., Dickson, D. W., Lowe, J., Emre, M., O’Brien, J. T., Feldman, H., Cummings, J., Duda, J. E., Lippa, C., Perry, E. K., Aarsland, D., Arai, H., Ballard, C. G., Boeve, B., Burn, D. J., Costa, D. Del Ser, T., Dubois, B., Galasko, D., Gauthier, S., Goetz, C. G., GomezTortosa, E., Halliday, G., Hansen, L. A., Hardy, J., Iwatsubo, T., Kalaria, R. N., Kaufer, D., Kenny, R. A., Korczyn, A., Kosaka, K., Lee, V. M., Lees, A., Litvan, I., Londos, E., Lopez, O. L., Minoshima, S., Mizuno, Y., Molina, J. A., Mukaetova-Ladinska, E. B., Pasquier, F., Perry, R. H., Schulz, J. B., Trojanowski, J. Q., Yamada, M., and 
Consortium on DLB. (2005). Diagnosis and management of dementia with Lewy bodies: third report of the DLB Consortium. Neurology 65, 1863-1872.

Menza, M., Dobkin, R. D., Marin, H., Mark, M. H., Gara, M., Buyske, S., Bienfait, K., and Dicke, A. (2009). A controlled trial of antidepressants in patients with Parkinson's disease and depression. Neurology 72, 886-892.

Menza, M. A., Robertson, H. D., and Bonapace, A. S. (1993). Parkinson's disease and anxiety: comorbidity with depression. Biol. Psychiatry 34, 465-470.

Metzler-Baddeley, C. (2007). A review of cognitive impairments in dementia with Lewy bodies relative to Alzheimer's disease and Parkinson's disease with dementia. Cortex 43, 583-600.

Morley, J. F., Xie, S. X., Hurtig, H. I., Stern, M. B., Colcher, A., Horn, S., Dahodwala, N., Duda, J. E., Weintraub, D., Chen-Plotkin, A. S., Van Deerlin, V., Falcone, D., and Siderowf, A. (2012). Genetic influences on cognitive decline in Parkinson's disease. Mov. Disord. 27, 512-518.

Mosimann, U. P., Mather, G., and Wesnes, K. A. (2004). Visual perception in Parkinson disease dementia and dmentia with Lewy bodies. Neurology 63, 2091-2096.

Muslimovic, D., Post, B., Speelman, J. D., and Schmand, B. (2005). Cognitive profile of patients with newly diagnosed Parkinson disease. Neurology 65, 1239-1245.

Neumann, J., Bras, J., Deas, E., O'Sullivan, S. S., Parkkinen, L., Lachmann, R. H., Li, A., Holton, J., Guerreiro, R., Paudel, R., Segarane, B., Singleton, A., Lees, A., Hardy, J., Houlden, H., Revesz, T., and Wood, N. W. (2009). Glucocerebrosidase mutations in clinical and pathologically proven Parkinson's disease. Brain 132, 1783-1794.

Nishioka, K., Ross, O. A., Vilariño-Güell, C., Cobb, S. A., Kachergus, J. M., Mann, D. M., Snowden, J., Richardson, A. M., Neary, D., Robinson, C. A., Rajput, A., Papapetropoulos, S., Mash, D. C., Pahwa, R., Lyons, K. E., Wszolek, Z. K., Dickson, D. W., and Farrer, M. J. (2011). Glucocerebrosidase mutations in diffuse Lewy body disease. Parkinsonism Relat. Disord. 17, 55-57.

Noe, E., Marder, K., Bell, K. L., Jacobs, D. M., Manly, J. J., and Stern, Y. (2004). Comparison of dementia with Lewy bodies to Alzheimer's disease and Parkinson's disease with dementia. Mov. Disord. 19, 60-67.
Olson, E. J., Boeve, B. F., and Silber, M. H. (2000). Rapid eye movement sleep behaviour disorder: demographic, clinical and laboratory findings in 93 cases. Brain 123, 331-339.

O’Mahony, D., Rowan, M., Feely, J., O'Neill, D., Walsh, J. B., and Coakley, D. (1993). Parkinson's dementia and Alzheimer's dementia: an evoked potential comparison. Gerontology 39, 228-240.

Ondo, W. G., Tintner, R., Voung, K. D., Lai, D., and Ringholz, G. (2005). Double-blind, placebo controlled, unforced titration parallel trial of quetiapine for dopaminergicinduced hallucinations in Parkinson's disease. Mov. Disord. 20, 958-963.

Owen, A. M., James, M., Leigh, P. N., Summers, B. A., Marsden, C. D., Quinn, N. P., Lange, K. W., and Robbins, T. W. (1992). Fronto-striatal cognitive deficits at different stages of Parkinson's disease. Brain 115, 1727-1751.

Pai, M. C., and Chan, S. H. (2001). Education and cognitive decline in Parkinson's disease: a study of 102 patients. Acta Neurol. Scand. 103, 243-247.

Papapetropoulos, S., Ellul, J., Polychronopoulos, P., and Chroni, E. (2004). A registry-based, casecontrol investigation of Parkinson's disease with and without cognitive impairment. Eur. J. Neurol. 11, 347-351.

Parkinson, J. (1817). An Essay on the Shaking Palsy. London: Sherwood, Neely, and Jones.

Pickering, R. M., Grimbergen, Y. A., Rigney, U., Ashburn, A., Mazibrada, G., Wood, B., Gray, P., Kerr, G., and Bloem, B. R. (2007). A meta-analysis of six prospective studies of falling in Parkinson's disease. Mov. Disord. 22, 1892-1900.

Pillon, B., Deweer, B., Agid, Y., and Dubois, B. (1993). Explicit memory in Alzheimer's, Huntington's, and Parkinson's diseases. Arch. Neurol. 50, 374-349.

Polymeropoulos, M. H., Lavedan, C., Leroy, E., Ide, S. E., Dehejia, A., Dutra, A., Pike, B., Root, H., Rubenstein, J., Boyer, R., Stenroos, E. S., Chandrasekharappa, S., Athanassiadou, A., Papapetropoulos, T., Johnson, W. G., Lazzarini, A. M., Duvoisin, R. C., Di Iorio, G., Golbe, L. I., and Nussbaum, R. L. (1997). Mutation in the alphasynuclein gene identified in families with Parkinson's disease. Science 276, 2045-2047.

Rabey, J. M., Prokhorov, T., Miniovitz, A., Dobronevsky, E., and Klein, C.
(2007). Effect of quetiapine in psychotic Parkinson's disease patients: a double-blind labeled study of 3 months' duration. Mov. Disord. 22, 313-318.

Rajput, A. H., Voll, A., Rajput, M. L., Robinson, C. A., and Rajput, A. (2009). Course in Parkinson disease subtypes: a 39-year clinicopathologic study. Neurology 73, 206-212.

Raskin, S., and Durst, R. (2010). Bupropion as the treatment of choice in depression associated with Parkinson's disease and it's various treatments. Med. Hypotheses 75, 544-546.

Reid, W. G., Broe, G. A., Hely, M. A., Morris, J. G., Williamson, P. M., O'Sullivan, D. J., Rail, D., Genge, S., and Moss, N. G. (1989). The neuropsychology of de novo patients with idiopathic Parkinson's disease: the effects of age of onset. Int. J. Neurosci. 48, 205-217.

Rogers, D., Lees, A. J., Smith, E., Trimble, M., and Stern, G. M. (1987). Bradyphrenia in Parkinson's disease and psychomotor retardation in depressive illness. An experimental study. Brain 110, 761-776.

Salmon, D. P., and Filoteo, J. V. (2007). Neuropsychology of cortical versus subcortical dementia syndromes. Semin. Neurol. 27, 7-21.

Savica, R., Rocca, W. A., and Ahlskog, J. E. (2010). When does Parkinson disease start? Arch. Neurol. 67, 798-801.

Schapira, A. H., and Tolosa, E. (2010). Molecular and clinical prodrome of Parkinson disease: implications for treatment. Nat. Rev. Neurol. 6, 309-317.

Schrag, A., Ben-Shlomo, Y., Brown, R., Marsden, C. D., and Quinn, N. (1998). Young-onset Parkinson's disease revisited - clinical features, natural history, and mortality. Mov. Disord. 13, 885-894.

Schrag, A., and Schott, J. M. (2006). Epidemiological, clinical, and genetic characteristics of early-onset parkinsonism. Lancet Neurol. 5, 355-363.

Selikhova, M., Williams, D. R., Kempster, P. A., Holton, J. L., Revesz, T., and Lees, A. J. (2009). A clinico-pathological study of subtypes in Parkinson's disease. Brain 132, 2947-2957.

Setó-Salvia, N., Clarimón, J., Pagonabarraga, J., Pascual-Sedano, B. Campolongo, A., Combarros, O., Mateo, J. I., Regaña, D., MartínezCorral, M., Marquié, M., Alcolea, D. Suárez-Calvet, M., Molina-Porcel, L., Dols, O., Gómez-Isla, T., Blesa, R., Lleó, A., and Kulisevsky, J. (2011). Dementia risk in Parkinson disease: disentangling the role of MAPT haplotypes. Arch. Neurol. 68, 359-364.

Setó-Salvia, N., Pagonabarraga, J., Houlden, H., Pascual-Sedano, B., Dols-Icardo, O., Tucci, A., PaisánRuiz, C., Campolongo, A., AntónAguirre, S., Martín, I., Muñoz, L. Bufill, E., Vilageliu, L., Grinberg, D., Cozar, M., Blesa, R., Lleó, A., Hardy, J., Kulisevsky, J., and Clarimón, J. (2012). Glucocerebrosidase mutations confer a greater risk of dementia during Parkinson's disease course. Mov. Disord. 3, 393-399.

Shachar, T., Lo Bianco, C., Recchia, A., Wiessner, C., Raas-Rothschild, A., and Futerman, A. H. (2011). Lysosomal storage disorders and Parkinson's disease: Gaucher disease and beyond. Mov. Disord. 26, 1593-1604.

Shotbolt, P., Samuel, M., Fox, C., and David, A. S. (2009). A randomized controlled trial of quetiapine for psychosis in Parkinson's disease. Neuropsychiatr. Dis. Treat. 5, 327-332.

Sidransky, E., Nalls, M. A., Aasly, J. O., Aharon-Peretz, J., Annesi, G., Barbosa, E. R., Bar-Shira, A., Berg, D., Bras, J., Brice, A., Chen, C. M., Clark, L. N., Condroyer, C., De Marco, E. V., Dürr, A., Eblan, M. J., Fahn, S., Farrer, M. J., Fung, H. C., Gan-Or, Z., Gasser, T., Gershoni-Baruch, R., Giladi, N., Griffith, A., Gurevich, T., Januario, C., Kropp, P., Lang, A. E., Lee-Chen G. J., Lesage, S., Marder, K., Mata, I. F., Mirelman, A., Mitsui, J., Mizuta, I., Nicoletti, G., Oliveira, C., Ottman, R., Orr-Urtreger, A., Pereira, L. V., Quattrone, A., Rogaeva, E., Rolfs, A., Rosenbaum, H., Rozenberg, R., Samii, A., Samaddar, T., Schulte, C., Sharma, M., Singleton, A., Spitz, M., Tan, E. K., Tayebi, N., Toda, T., Troiano, A. R., Tsuji, S., Wittstock, M., Wolfsberg, T. G., Wu, Y. R., Zabetian, C. P., Zhao, Y., and Ziegler, S. G. (2009). Multicenter analysis of glucocerebrosidase mutations in Parkinson's disease. N. Engl. J. Med. 361, 1651-1661.

Spira, P. J., Sharpe, D. M., Halliday, G., Cavanagh, J., and Nicholson, G. A. (2001). Clinical and pathological features of a Parkinsonian syndrome in a family with an Ala53Thr alphasynuclein mutation. Ann. Neurol.49, 313-319.

Starkstein, S. E., Sabe, L., and Petracca, G. (1996). Neuropsychological and psychiatric differences between Alzheimer's disease and Parkinson's disease with dementia. J. Neurol. Neurosurg. Psychiatr. 61, 381-387.

Steinlechner, S., Stahlberg, J., Völkel, B., Djarmati, A., Hagenah, J., Hiller, A., Hedrich, K., König, I., Klein, C., and 
Lencer, R. (2007). Co-occurrence of affective and schizophrenia spectrum disorders with PINK1 mutations. J. Neurol. Neurosurg. Psychiatr. 78, 532-535.

Stern, Y., Marder, K., Tang, M. X., and Mayeux, R. (1993). Antecedent clinical features associated with dementia in Parkinson's disease. Neurology 43, 1690-1692.

Stuss, D. T. (2011). Functions of the frontal lobes: relation to executive functions. J. Int. Neuropsychol. Soc. 17, 759-765.

Taipa, R., Pinho, J., and Melo-Pires, M. (2012). Clinico-pathological correlations of the most common neurodegenerative dementias. Front. Neurol. 3:68. doi:10.3389/ fneur.2012.00068

Tan, E. K., and Jankovic, J. (2006). Genetic testing in Parkinson disease: promises and pitfalls. Arch. Neurol. 63, 1232-1237.

Terzaghi, M., Sinforiani, E., and Zucchella, C. (2008). Cognitive performance in REM sleep behaviour disorder: a possible early marker of neurodegenerative disease? Sleep Med. 9, 343-351.

The Parkinson Study Group. (1999). Low-dose clozapine for the treatment of drug-induced psychosis in Parkinson's disease. N. Engl. J. Med. 340, 757-763.

Tolosa, E., Gaig, C., Santamaría, J., and Compta, Y. (2009). Diagnosis and the premotor phase of Parkinson disease. Neurology 27, S12-S20.

Tröster, A. I. (2008). Neuropsychological characteristics of dementia with Lewy bodies and Parkinson's disease with dementia: differentiation, early detection, and implications for "mild cognitive impairment" and biomarkers. Neuropsychol. Rev. 18, 103-119.

Trotta, L., Guella, I., Soldà, G., Sironi, F., Tesei, S., Canesi, M., Pezzoli, G., Goldwurm, S., Duga, S., and Asselta, R. (2012). SNCA and MAPT genes: Independent and joint effects in Parkinson disease in the Italian population. Parkinsonism Relat. Disord. 18, 257-162.

Turner, M. A., Moran, N. F., and Kopelman, M. D. (2002). Subcortical dementia. Br. J. Psychiatry 180, 148-151.

Valente, E. M., Abou-Sleiman, P. M., Caputo, V., Muqit, M. M., Harvey, K., Gispert, S., Ali, Z., Del Turco, D., Bentivoglio, A. R., Healy, D. G., Albanese, A., Nussbaum, R., González-Maldonado, R., Deller,
T., Salvi, S., Cortelli, P., Gilks, W. P., Latchman, D. S., Harvey, R. J., Dallapiccola, B., Auburger, G., and Wood, N. W. (2004). Hereditary early-onset Parkinson's disease caused by mutations in PINK1. Science 304, 1158-1160.

Valente, E. M., Bentivoglio, A. R., Dixon, P. H., Ferraris, A., Ialongo, T., Frontali, M., Albanese, A., and Wood, N. W. (2001). Localization of a novel locus for autosomal recessive early-onset parkinsonism, PARK6, on human chromosome 1p35-p36. Am. J. Hum. Genet. 68, 895-900.

Valente, E. M., Brancati, F., Ferraris, A., Graham, E. A., Davis, M. B., Breteler, M. M., Gasser, T., Bonifati, V., Bentivoglio, A. R., De Michele, G., Dürr, A., Cortelli, P., Wassilowsky, D., Harhangi, B. S., Rawal, N., Caputo, V., Filla, A., Meco, G., Oostra, B. A., Brice, A., Albanese, A., Dallapiccola, B., Wood, N. W., and European Consortium on Genetic Susceptibility in Parkinson's Disease. (2002). PARK6linked parkinsonism occurs in several European families. Ann. Neurol. 51, 14-18.

van Duijn, C. M., Dekker, M. C., Bonifati, V., Galjaard, R. J., HouwingDuistermaat, J. J., Snijders, P. J., Testers, L., Breedveld, G. J., Horstink, M., Sandkuijl, L. A., van Swieten, J. C., Oostra, B. A., and Heutink, P. (2001). Park7, a novel locus for autosomal recessive earlyonset parkinsonism, on chromosome 1p36. Am. J. Hum. Genet. 69, 629-634.

Velayati, A., Yu, W. H., and Sidransky, E. (2010). The role of glucocerebrosidase mutations in Parkinson disease and Lewy body disorders. Curr. Neurol. Neurosci. Rep. 10, 190-198.

Wattjes, M. P. (2011). Structural MRI. Int. Psychogeriatr. 23(Suppl. 2), S13-S24.

Weintraub, D., and Burn, D. J. (2011). Parkinson's disease: the quintessential neuropsychiatric disorder. Mov. Disord. 26, 1022-1031.

Weintraub, D., Taraborelli, D., Morales, K. H., Duda, J. E., Katz, I. R., and Stern, M. B. (2006). Escitalopram for major depression in Parkinson's disease: an open-label, flexible-dosage study. J. Neuropsychiatry Clin. Neurosci. 18, 377-383.

Weintraub, S., Wicklund, A. H., and Salmon, D. P. (2012). The neuropsychological profile of Alzheimer disease. Cold Spring Harb. Perspect. Med. 2, a006171.
Wermuth, L., Sorensen, P. S., Timm, S., Christensen, B., Utzon, N. P., Boas, J., Dupont, E., Hansen, E. Magnussen, I., Mikkelsen, B., WormPetersen, J., Lauritzen, L., Bayer, L. and Bech, P. (1998). Depression in idiopathic Parkinson's disease treated with citalopram: a placebocontrolled trial. Nord. J. Psychiatry 52, 163-169.

Wickremaratchi, M. M., Majounie, E., Morris, H. R., Williams, N. M. Lewis, H., Gill, S. S., Khan, S., Heywood, P., Hardy, J., Wiles, C. M., Singleton, A. B., and Quinn, N. P. (2009). Parkin-related disease clinically diagnosed as a pallidopyramidal syndrome. Mov. Disord. 24, 138-140.

Williams, D. R., and Lees, A. J. (2005). Visual hallucinations in the diagnosis of idiopathic Parkinson's disease: a retrospective autopsy study. Lance Neurol. 4, 605-610.

Williams-Gray, C. H., Evans, J. R., Goris, A., Foltynie, T., Ban, M., Robbins, T. W., Brayne, C., Kolachana, B. S., Weinberger, D. R., Sawcer, S. J. and Barker, R. A. (2009). The distinct cognitive syndromes of Parkinson's disease: 5 year follow-up of the CamPaIGN cohort. Brain 132, 2958-2969.

Winblad, B., Cummings, J., Andreasen, N., Grossberg, G., Onofrj, M., Sadowsky, C., Zechner, S., Nagel, J., and Lane, R. (2007). A sixmonth double-blind, randomized, placebo-controlled study of a transdermal patch in Alzheimer's disease - rivastigmine patch versus capsule. Int. J. Geriatr. Psychiatry 22, 456-567.

Winge, K., and Fowler, C. J. (2006). Bladder dysfunction in Parkinsonism: mechanisms, prevalence, symptoms, and management. Mov. Disord. 21, 737-745.

Wood, B. H., Bilclough, J. A., Bowron, A., and Walker, R. W. (2002). Incidence and prediction of falls in Parkinson's disease: a prospective multidisciplinary study. J. Neurol. Neurosurg. Psychiatr. 72, 721-725.

Wszolek, Z. K., Pfeiffer, R. F., Tsuboi, Y. Uitti, R. J., McComb, R. D., Stoessl, A. J., Strongosky, A. J., Zimprich, A., Müller-Myhsok, B., Farrer, M. J., Gasser, T., Calne, D. B., and Dickson, D. W. (2004). Autosomal dominant parkinsonism associated with variable synuclein and tau pathology. Neurology 62, 1619-1622.

Zarranz, J. J., Alegre, J., Gómez-Esteban, J. C., Lezcano, E., Ros, R., Ampuero,
I., Vidal, L., Hoenicka, J., Rodriguez, O., Atarés, B., Llorens, V., Gomez Tortosa, E., del Ser, T., Muñoz, D. G., and de Yebenes, J. G. (2004). The new mutation, E46K, of alpha-synuclein causes Parkinson and Lewy body dementia. Ann. Neurol. 55, 164-173.

Zaluska, M., and Dyduch, A. (2011). Bupropion in the treatment of depression in Parkinson's disease. Int. Psychogeriatr. 23, 325-327.

Zesiewicz, T. A., Sullivan, K. L., Arnulf, I., Chaudhuri, K. R., Morgan, J. C., Gronseth, G. S., Miyasaki, J., Iverson, D. J., and Weiner, W. J. (2010). Quality Standards Subcommittee of the American Academy of Neurology. Practice Parameter: treatment of nonmotor symptoms of Parkinson disease: report of the Quality Standards Subcommittee of the American Academy of Neurology. Neurology 74, 924-931.

Zoldan, J., Friedberg, G., Livneh, M., and Melamed, E. (1995). Psychosis in advanced Parkinson's disease: treatment with ondansetron, a 5-HT3 receptor antagonist. Neurology 45, 1305-1308.

Conflict of Interest Statement: Joana Meireles has received financial support to attend meetings from Biogen Idec and Novartis companies. João Massano has acted as an advisor and received honoraria and financial support to speak or attend meetings from Bial, Grünenthal, Lundbeck, Novartis, and Tecnifar companies. Off label drug therapies are discussed in the text, for which the authors are exclusively responsible.

Received: 24 February 2012; paper pending published: 22 March 2012; accepted: 07 May 2012; published online: 25 May 2012.

Citation: Meireles $J$ and Massano J (2012) Cognitive impairment and dementia in Parkinson's disease: clinical features, diagnosis, and management. Front. Neur. 3:88. doi: 10.3389/fneur.2012.00088

This article was submitted to Frontiers in Dementia, a specialty of Frontiers in Neurology.

Copyright (C) 2012 Meireles and Massano. This is an open-access article distributed under the terms of the Creative Commons Attribution Non Commercial License, which permits noncommercial use, distribution, and reproduction in other forums, provided the original authors and source are credited. 